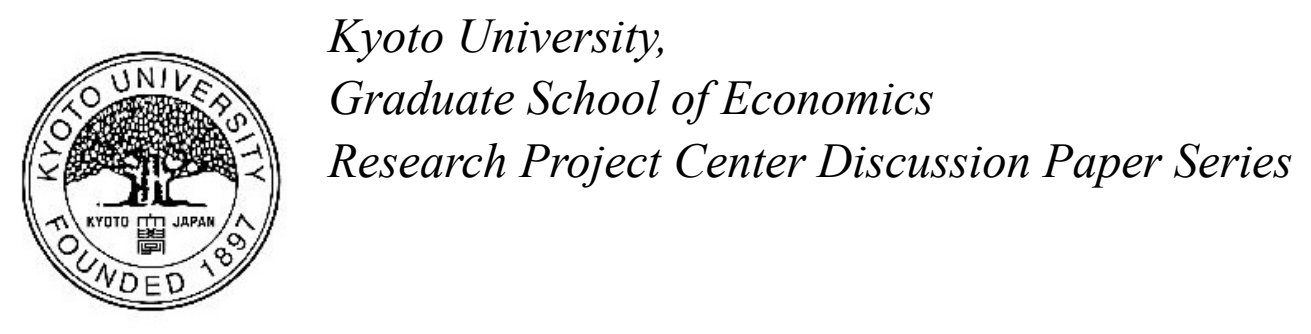

Structural Change and Transformation of Growth Regime in the Japanese Economy

\author{
Hiroshi Nishi
}

Discussion Paper No. E-15-001

\author{
Research Project Center \\ Graduate School of Economics \\ Kyoto University \\ Yoshida-Hommachi, Sakyo-ku \\ Kyoto City, 606-8501, Japan
}

April, 2015 


\title{
Structural Change and Transformation of Growth Regime in the Japanese Economy
}

\author{
Hiroshi NISHI* \\ Hannan University \\ (Original version: April 2015)
}

\begin{abstract}
The purpose of this study is to empirically examine the relationship between structural change and economic growth in Japan during the past 40 years. While using the growth in real value added and labour productivity as measurement of economic growth, we consider the structural change in value added as the structural change in output and that in capital and labour as the structural change in inputs. Specifically, we use the Japan Industrial Productivity database 2014 compiled by the Research Institute of Economy, Trade and Industry, and show (1) the pace of structural change in inputs and output, (2) the evolution of sectoral dispersion of economic growth, (3) the changing distribution of sectoral contribution to aggregate economic growth, and (4) empirical evidence of the relationship between structural change and economic growth. Our main conclusion is that the Japanese growth regime has transformed from a heterogeneity decreased regime with overall growth process to a heterogeneity increased one with uneven growth process since the 1990s; the impact that structural change in output had on economic growth was positive, although its magnitude has weakened since then.
\end{abstract}

Keywords: Growth regime, Sectoral heterogeneity, Structural change, Japanese economy

JEL Classification: B50, E12, L16, O41

${ }^{*}$ Faculty of Economics, Hannan University, 5-4-33, Amami Higashi, Matsubara-shi, Osaka 580-8502, Japan. E-mail: nishi@hannan-u.ac.jp 


\section{Introduction}

This study examines the interrelationship between economic growth and structural change in the Japanese economy. We show how structural changes in inputs and output in the various sectors of the Japanese economy affect its economic growth and stagnation. In this study, we use a disaggregation approach and divide the macroeconomy into sectors on the basis of the Japan Industrial Productivity (JIP) database 2014 compiled by the Research Institute of Economy, Trade and Industry (RIETI). The disaggregation approach is important because, as we will see below, sectoral performances such as growth of labour productivity and value added are not always uniform among sectors and thus sectoral heterogeneity is evolving in Japan.

This study is based on the growth regime analysis of the régulationists and post-Keynesians. We also try to empirically expand these theories from a multi-sectoral perspective. The régulationists and post-Keynesians have analysed the economic growth regime of a country from a macroeconomic perspective (Boyer and Yamada (2000); Boyer et al. (2011); Lavoie and Stockhammer (2013); Hein (2014)). They reduced the dynamic relationship between productivity growth and demand growth into two equations, namely, the demand regime and productivity regime, and revealed different constellation of these regimes in terms of country and period.

Since such macroeconomic analysis is conducted at the aggregate level, we assume no sectorally heterogeneous configuration and structural change. Therefore, we cannot capture the relationship between macroeconomic performance and industrial structure. Even if a macroeconomy reveals an average growth rate in each period, there could be higher growth sectors that lead the aggregate growth and lower ones that stagnate growth in the economy. In other words, even if the aggregate growth rate is unique, it is important to recognize that in reality it is the result of sectorally heterogeneous contributions.

Uemura and Tahara (2014) is a recent contribution that overcomes such issues in aggregate analysis. Their multi-sectoral approach integrally analyses the growth regime as well as deindustrialization mechanism in Japan. The study shows that the Japanese economy has undergone both positive and negative de-industrialization, depending especially on the performance of the export-core manufacturing sectors over the past 30 years. Existing literature has tackled the relationship between structural change and aggregate economic growth. ${ }^{1}$ One of the most

\footnotetext{
${ }^{1}$ Krüger (2008a) is a comprehensive survey on structural change, economic growth, and productivity. The study reviews the development of the classical three main sector model, multi-sector growth models, evolutionary theories,
} 
important research lines originates from Baumol (1967). According to this study, there is negative feedback on economic growth in the process of tertiarization, in what is well known as 'Baumol's disease'. Studies after Baumol have attempted to see whether expansion in a nonprogressive sector has a negative impact on the overall economic growth. These studies consider expansion of the tertiary sector, also classified as a non-progressive low-productivity sector, as structural change. While some studies support Baumol's prediction (Baumol et al. (1985); Peneder (2003); Nordhaus (2008); Hartwig (2011, 2012)), others present negative results for this prediction ((Maroto-Sánchez and Cuadrado-Roura (2009); Dietrich (2012)).

While the existing literature focuses mainly on the EU and the US, recent studies on Japan (Fukao and Miyagawa (2008); Ito and Lechevalier (2009); Fukao (2012); Morikawa (2014)) focus on the industrial structure and attempt to find the cause and consequence of different performance at the industrial and firm level. They focus on the supply side, with the investigation of total factor productivity (TFP) growth certainly the most popular. Papers in Fukao and Miyagawa (2008) indicate that the TFP growth rate differs at the industrial and firm level. Fukao (2012) emphasizes that as the cause of slowdown in TFP growth, Japan lags behind in ICT investment. Morikawa (2014) intensively investigates the economic performance of the services sector and finds that the productivity of firms in the services sector is not necessarily low. He points out that there are a number of high-productivity firms in this sector. Ito and Lechevalier (2009) focus on the dispersion of productivity growth across heterogeneous firms. They find evidence that internationalization has a significant and positive impact on productivity dispersion.

Almost all of these studies point out the heterogeneity of industries and firms. This means that by examining the variables at an average or aggregate level, we cannot correctly understand the overall economic performance. Instead, we need to observe the sectoral distribution that creates the aggregate outcomes. Even though the aggregation approach is useful to analyse the growth process before the 1980s, it cannot explain the uneven growth process after the 1990s, as we will show in this study. The uneven growth process after the 1990s is not satisfactorily explained even by Uemura and Tahara (2014), because they do not consider the distribution of the sectors contributing to economic growth.

It is in this context that we introduce the multi-sectoral perspective to the growth regime analysis of the post-Keynesians and régulationists. The first novelty of this study is that we shed light

and empirical studies. 
on the sectoral distribution behind economic growth. In other words, we attempt to investigate the industrial foundation of the growth regime. The second novelty is that to examine the Japanese economic growth and stagnation, we introduce structural change in various sectors. In doing so, we investigate the change in sectoral structure of inputs and output in relation to economic growth. To be more precise, the structural change in output means the change in sectoral composition of value added, which is a proxy for effective demand structure. The structural change in inputs means change in sectoral share of factors of production such as labour and capital. Thus, we also consider the demand side of sectoral performance, which the existing literature has not adequately examined. Hence, the third novelty of this study is that we empirically detect the kind of structural change required to promote economic growth.

The remainder of this paper is organized as follows. Section 2 introduces sectoral classification based on the JIP database 2014. This section also presents the indices used to measure the degree of structural change in this paper. Section 3 considers the Japanese sectoral performance and macroeconomic growth. This section illustrates first the structural change in inputs and output, second the sectoral contribution to growth, and finally the changing configuration of the leading and stagnating sectors in Japan for the past 40 years. Section 4 presents our econometric analysis. This section reports the impact of structural changes in inputs and output on economic growth. Finally, Section 5 concludes the paper.

\section{Measurement of structural change}

\subsection{JIP database and sectoral classification}

We use the JIP database 2014 compiled by RIETI throughout our empirical analysis in this study. The JIP database 2014 consists of various types of annual data for the period 1970-2011 required to estimate the economic activities in 108 industries covering the Japanese economy. Because to investigate structural change we need to consider the changes affecting disaggregate units, we require statistical data that can capture multi-sectoral performance. The JIP database of RIETI is one of the most appropriate databases for this purpose.

This study defines 106 sectors as a small classification and mainly considers their economic performance and relationship with the aggregate economic outcome. The housing sector (JIP classification no. 72) and activities not classified elsewhere (JIP classification no. 108) are ex- 
cluded, because some important data such as number of workers and man-hours are not available for our estimation.

Our growth analysis explains the growth in value added and labour productivity on the basis of the 106 sectors' performance. While such an approach allows us to find the relationship between sectoral behaviour and macroeconomic growth in more detail, it is still not clear in some cases as to how macroeconomic performance is related to sectoral economic performance. For example, the macroeconomic trend is not clear when we try to explain macroeconomic phenomena on the basis of small sectoral performance since the sector may be too small to have an impact on macroeconomic performance. In addition, in empirical analysis, some structural change indices cannot be constructed for each of the 106 sectors in the JIP database, but have to be constructed by gathering data from similar sectors. In these cases, we aggregate numerous small classifications into a large and intermediate classification. For the large and intermediate classification, we follow the classification method employed by Franke and Kalmbach (2005) and Uemura and Tahara (2014). Table 1 summarizes the correspondence between the small, intermediate, and large classifications.

Table 1: Large, medium and small classification based on JIP database

\begin{tabular}{ll|ll|l}
\hline \hline \multicolumn{1}{c|}{ Code in Large classification } & \multicolumn{2}{|c|}{ Code in Intermediate classification } & Original no. in JIP (Small classification) \\
\hline \hline \multirow{2}{*}{ L1 (5.66\%) } & \multirow{2}{*}{ Agriculture } & M1 (5.66\%) & Agriculture & $1-6$ \\
\hline \multirow{3}{*}{ L2 (57.55\%) } & \multirow{2}{*}{ Manufacturing } & M2 (15.09\%) & Export-core manufacturing & $42-57$ \\
& & M3 (34.91\%) & Other manufacturing & $8-41,58-59,92$ \\
& M4 (7.55\%) & Other industries & $7,60-66$ \\
\hline \multirow{3}{*}{ L3 (36.79\%) } & \multirow{2}{*}{ Service } & M5 (5.66\%) & Business-related services in a narrow sense & $67,69,73-79,81,99,106$ \\
& & M6 (10.38\%) & Business-related services in a broad sense & $85-88,91$ \\
& & M7 (9.43\%) & Consumer services & $68,70-72,89-90,93-97$ \\
& M8 (11.32\%) & Public services & $80,82-84,98,100-105,107$ \\
\hline \hline
\end{tabular}

Note: By author on the basis of JIP 2014 and Uemura and Tahara (2014). Percentage in parenthesis for intermediate and large classifications indicates the share of each class in total sectors.

The large classification is based on the standard classification of agriculture, manufacturing, and services sectors. The agriculture sector (L1) directly corresponds to the agriculture sector M1; the manufacturing sector (L2) corresponds to M2, M3, and M4; and the services sector (L3) include M5, M6, M7 and M8. ${ }^{2}$

\footnotetext{
${ }^{2}$ To be more precise, the intermediate classification in Uemura and Tahara (2014) is as follows: The agriculture
} 
Uemura and Tahara (2014) present some characteristics of intermediate classification. First, with regard to real output, the export-core manufacturing industry has shown the strongest response to fluctuations in external demand whereas the business-related services sector has fluctuated almost in line with the export-core manufacturing industry. Second, with regard to capital accumulation rate, the accumulation rate increased sharply in the export-core manufacturing industry during the bubble boom of the late 1980s; capital accumulation also increased in the business-related services sector. Finally, with regard to labour productivity growth, the exportcore manufacturing industry shows high labour productivity growth with large fluctuations, although labour productivity in the other manufacturing sectors remains at a relatively low level. In contrast, the growth rate of labour productivity in the services sector is not unique. The businessrelated services sectors in both the narrow and broad sense show relatively high growth rates.

\subsection{Indices of structural change}

It is well known that theoretically structural changes occur in both the demand and supply sides (Baumol (1967); Pasinetti (1993)). A structural change in demand occurs on account of a change in relative prices, consumers' preference for higher quality, different income elasticities, and increasing saturation of demand for existing goods. As the demand for each sector grows at a different rate in the process of economic growth, the process influences the quantity and composition of the goods demanded from different industries. On the supply side, learning and technological change can lead to productivity improvement, which enables firms to produce the same goods at lower unit cost, or to create new goods frequently and thus attract new effective demand. In the

sector (M1) includes agriculture, forestry, fisheries, livestock, and sericulture farming. The export-core manufacturing sector (M2) mainly consists of transportation equipment, general machinery, electronic and electrical equipment, and precision machinery and equipment. The other manufacturing sector (M3) mainly includes textile, office, and service industry machines. They thus classified the manufacturing industry into the export-core manufacturing industry with high export ratio and other manufacturing industries. The other industry (M4) includes construction, electricity and gas, water supply, mining, and so on. The services industry is classified into business-related services in a narrow sense (M5), business-related services in a broad sense (M6), consumer services, and public services. The business-related services in a narrow sense include finance, rental of office equipment and goods, advertisement, information services, and internet-based services, whereas the business-related services in a broad sense include wholesale, research, telegraph and telephone, mail, and transportation. The consumer services (M7) consist of retail, insurance, real estate, broadcasting, entertainment, eating and drinking places, and accommodation. Finally, the public service sector (M8) mainly includes education, medical services, and hygiene. 
process of economic growth, the sectoral productivity grows at different rates. The interaction of these factors leads to sectorally different growth rates of output, inputs, and productivity. One of the consequences of structural change is therefore the change in sectoral share of output and inputs. $^{3}$

In order to investigate the structural change process, we need some indices to quantify its magnitude. We use the structural change indices to summarize the changes in sectoral composition of an economy between two points in time. This study takes the two indices used in Dietrich (2012) because they are based on the sectoral share for an economic variable and are thus appropriate to consider structural change. ${ }^{4}$

The first index is the norm of absolute value (NAV), the simplest index to measure structural change. Let $x_{i, t}$ be the share of sector $i=1, \ldots n$ at time $t=1, \ldots T-1$ and $s=2, \ldots T$. This index can be given by the following calculation:

$$
\mathrm{NAV}_{s, t}=0.5 \sum_{i=1}^{n}\left|x_{i, s}-x_{i, t}\right|
$$

The result is a range of NAV between zero and unity, so that the interpretation of NAV is quite simple. This indicates that the structural change is exactly equal to the share of movement of sectors as a percentage of the whole economy. According to Dietrich (2012): 'If the structure remains unchanged, the index is equal to zero, and if the change in all sectors is at its highestmeaning the whole economy undergoes a total change — then the index is equal to unity' (ibid, p.920).

The second index to measure the degree of structural change is the modified Lilien index

\footnotetext{
${ }^{3}$ The so-called de-industrialization is a well-known example of such structural change. According to related literature (e.g., Rowthorn and Wells (1987)), 'de-industrialization' means the decreasing share of employment in the industrial (manufacturing) sector.

${ }^{4}$ We employ the following two indices to measure the degree of structural change. Naturally, there are some other indices to measure structural change. For instance, Wolff (2002) constructs a structural change index on the basis of the similarity index for two time periods 1 and 2, which is similar to the following equation:

$$
S C I^{12}=1-\frac{\sum_{i} x_{i}^{1} x_{i}^{2}}{\sqrt{\left(\sum_{i} x_{i}^{1}\right)^{2}\left(\sum_{i} x_{i}^{2}\right)^{2}}}
$$

where $x_{i}$ is sector $i$ 's share of variable in the total economy. The value is close to unity when the structural change in that variable takes place at a high pace. We similarly calculate the structural change index for value added and employment. Although we do not report this in detail here, their tendency is not drastically different from NAV and MLI.
} 
(MLI), which is based on Lilien (1982). Lilien (1982) and was originally introduced as an index to measure the standard deviation of the sectoral growth rate of demand for labour from period $s$ to period $t$ and employed to measure the degree of liquidity of factor reallocation. However, in this study, we use a modified version of this index to capture the degree of structural change. Dietrich (2012) presents a modified version of the Lilien index by augmenting it with weighting by the share of sectors in both periods.

$$
\operatorname{MLI}_{s, t}=\sqrt{\sum_{i=1}^{n} x_{i, s} \cdot x_{i, t} \cdot\left(\log \frac{x_{i, s}}{x_{i, t}}\right)^{2}}
$$

When the MLI is low, the structural change in the economy is at a slow pace; a high MLI means that the structural change is at a high pace. ${ }^{5}$

From these calculations, we construct the structural change index for value added, employment, capital stock, and capital-labour ratio. The structural change index for value added reflects the speed of change in sectoral output share. The structural change indices for employment, capital stock, and capital-labour ratio reflect the speed of change in sectoral inputs share. These are also interpreted as approximations of the structural changes in the demand and supply sides. Labour and capital are the principal factors of production. A change in these inputs can lead to changes in output and productivity and thus may accelerate or decelerate economic growth. In addition, the combination of capital and labour, which reflects the technological level of production, also matters for economic growth. Thus, these are what determine the supply side structure. The value added can be determined by not only the supply side but also the demand side. For example, Engel's law predicts that a higher income per capita results in a shifting demand structure. Moreover, an innovation that attracts new effective demand in a sector also contributes to the growth in value added in that sector. Thus, these factors lead to changes in the sectoral composition of value added, meaning that the sectoral composition of value added is not independent of the demand side structure. ${ }^{6}$

\footnotetext{
${ }^{5}$ Ansari et al. (2013) introduce the modified Lilien measure as a desirable indicator of structural change that ideally fulfils the following five necessary conditions: (1) the index should take the value of zero if there are no structural changes within one period, (2) the structural change between two periods should be independent of the time sequence, (3) the structural change in one period should be smaller or equal to that between two sub-periods, (4) the index should be a dispersion measure, and (5) the index should consider the weight (size) of the sectors. The Lilien index violates conditions (2) and (3), whereas the modified Lilien index fulfils all the necessary conditions.

${ }^{6}$ Besides, the final demand by sector in the JIP database Input-Output table is also appropriate to capture the
} 


\section{Sectoral performance and macroeconomic growth}

\subsection{Structural change and changing sectoral heterogeneity}

This section explores the overall trends in structural change in inputs and output in Japan by examining the annual and 5-year evolution of structural change indices. The structural change indices are based on both the small classification (106 sectors) and intermediate classification (8 sectors). For details of the data sources and construction of the variables introduced in this study, see the panel data analysis in the following section.

Figure 1 shows the annual and 5-year structural change index calculations of value added in real terms. The annual variation demonstrates that the structural change in value added was relatively stable from 1973 to the mid-1990s, except for outliers at the beginning of the 1980s. Although the speed of structural change differs from period to period, the speed until the 1990s of the lost decade remained almost the same as the previous decade. What is clear from the figure for both calculations is that the structural change in value added began to accelerate gradually since the mid-1990s.

Figures 2 to 4 show results of structural change indices for employment, capital, and capitallabour ratio for annual and 5-year terms. As these are the principal factors of production, they reflect the structural change in terms of inputs and technology. From figure 2, the structural change in employment shows a slightly decreasing trend, with cyclical behaviour from the 1970s to the 1990s. After the 1990s, the cyclical behaviour continues, but it is hard to read a clear trend from the figure.

Figure 3 shows the structural change indices for capital stock for annual and 5-year terms. In the 1970s, the pace of structural change in capital stock was high historically. However, these indices show a rather clear trend in the long run. The pace of structural change in capital stock is seen to constantly decrease until recently, except for a short-run high pace during the bubble period of the 1980s, which could have resulted in the excess capital accumulation of the 1990s. The pace of structural change after the bubble burst decelerated, and became especially slow during the recent 10 years.

demand side dynamics. However, since some data of demand components are not available in this sheet, we cannot conduct the statistical analysis smoothly. Therefore, we employ value added to capture the demand side of the economy. For the statistical processing relationship between value added and final demand, see the JIP database 2014 website of RIETI. 


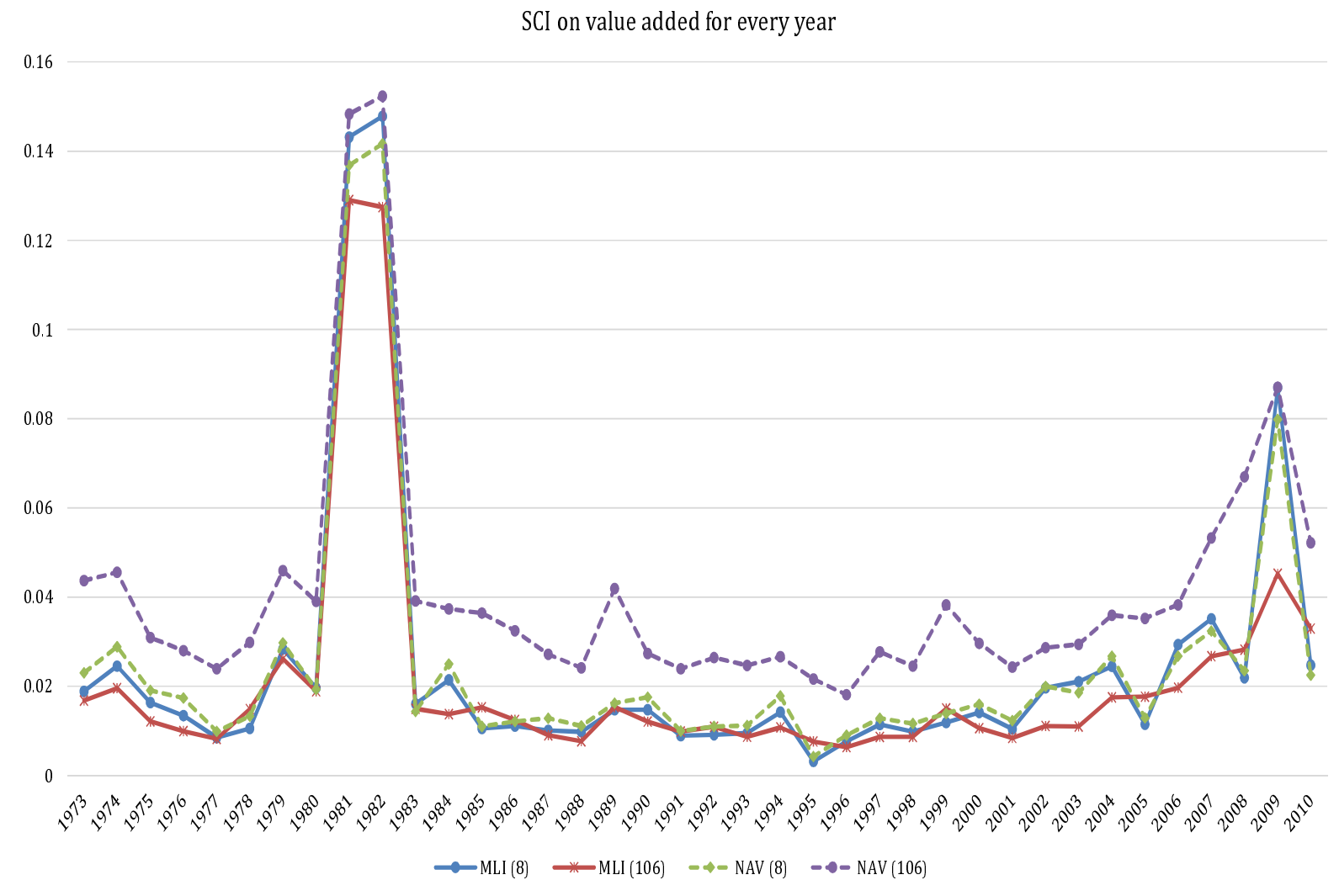

SCI on value added for 5 years

0.18

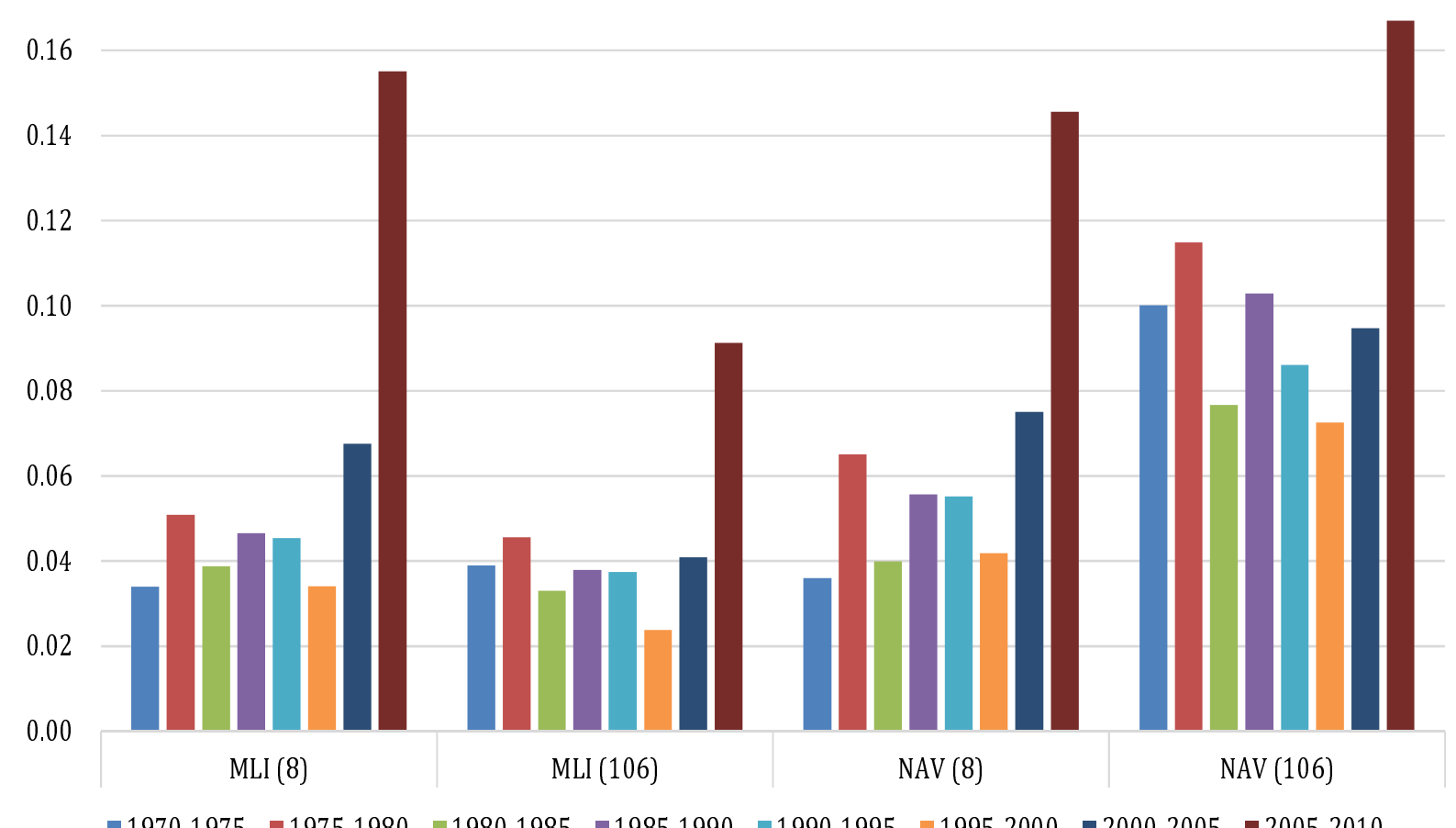

Note: From the author's calculation based on the JIP database 2014.

Figure 1: Structural change indices for annual and 5-year terms (value added) 


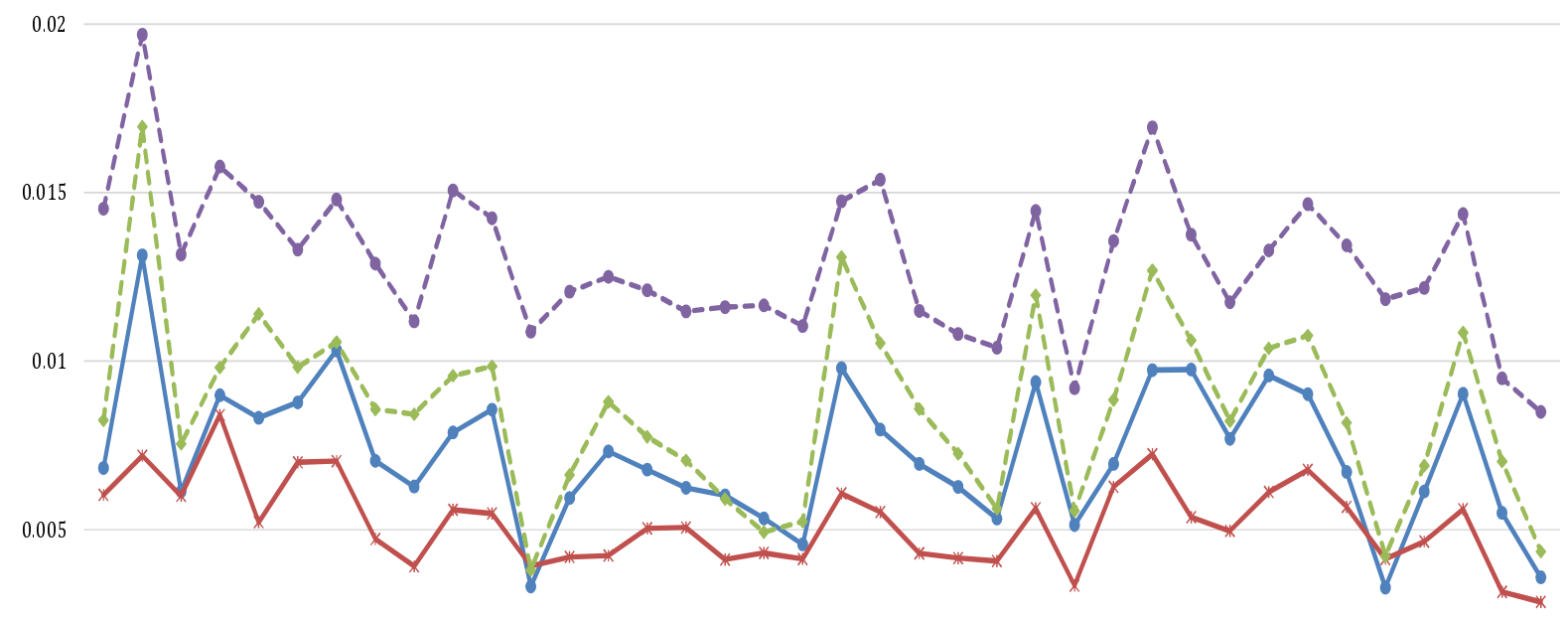

0

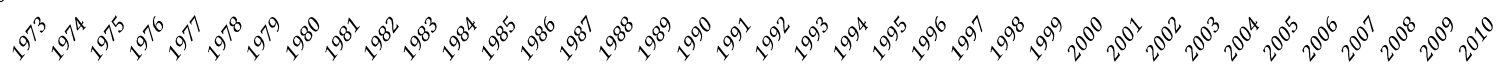
$\rightarrow \operatorname{MLI}(8) \quad$ *MLI(106) $\rightarrow-\operatorname{NAV}(8) \quad--\operatorname{NAV}(106)$

SCl on employment for 5 years

0.08

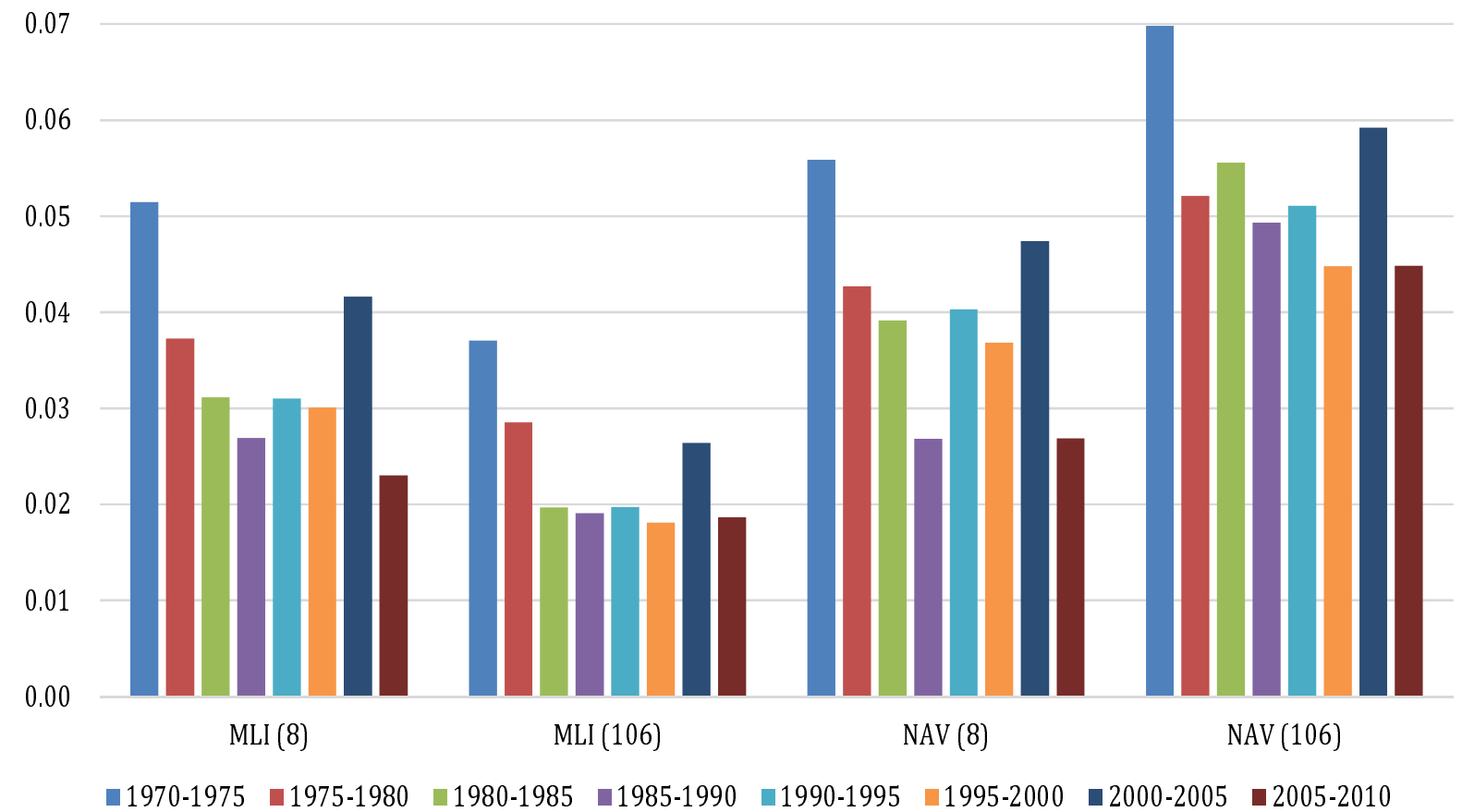

Note: From the author's calculation based on the JIP database 2014.

Figure 2: Structural change indices for annual and 5-year terms (employment) 


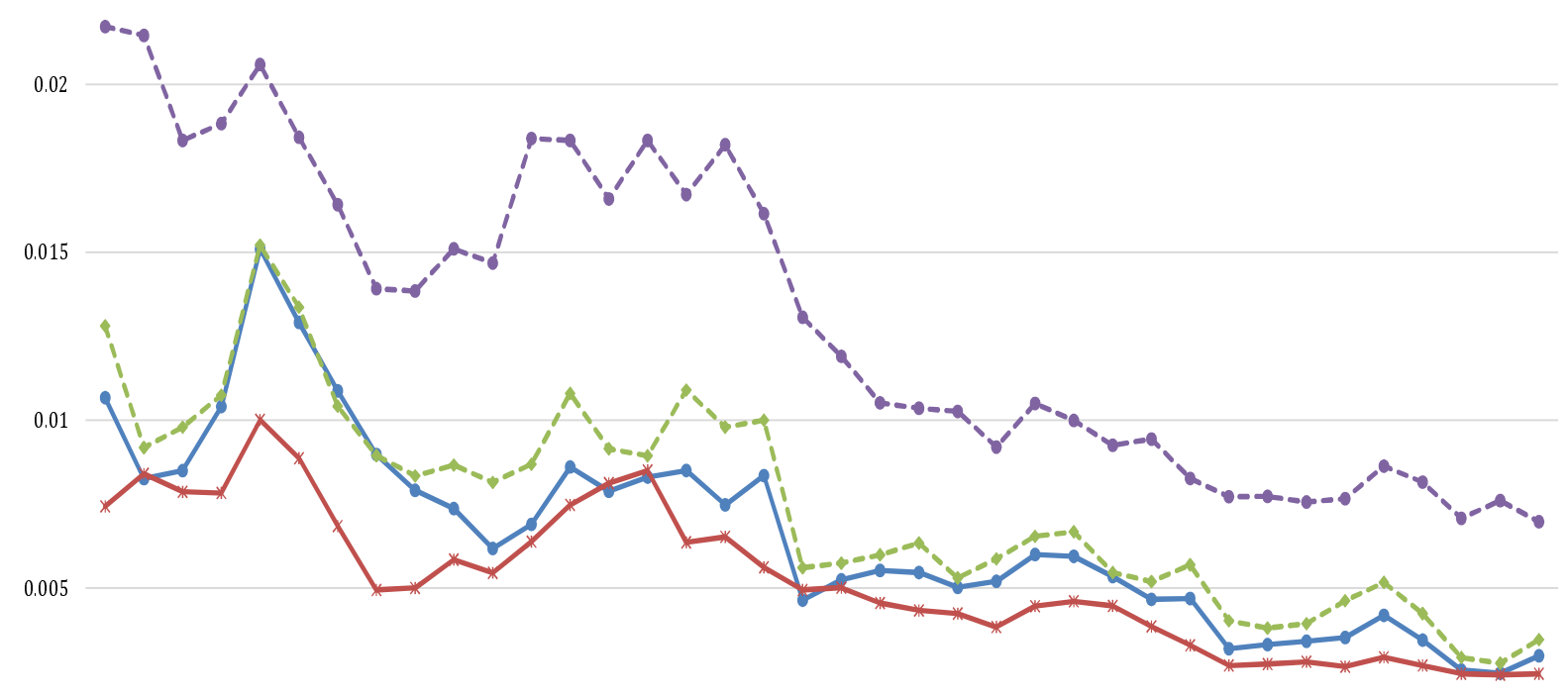

0

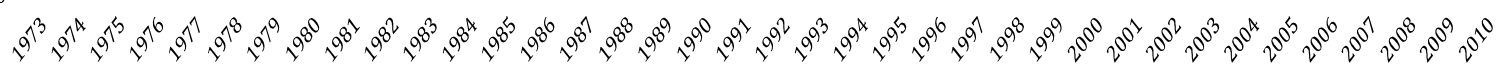
$\rightarrow$ MLI (8) $\quad$ MLI(106) $\rightarrow-\operatorname{NAV}(8) \quad--\operatorname{NAV}(106)$

\section{SCI on capital for 5 years}

0.14

0.12

0.10

0.08

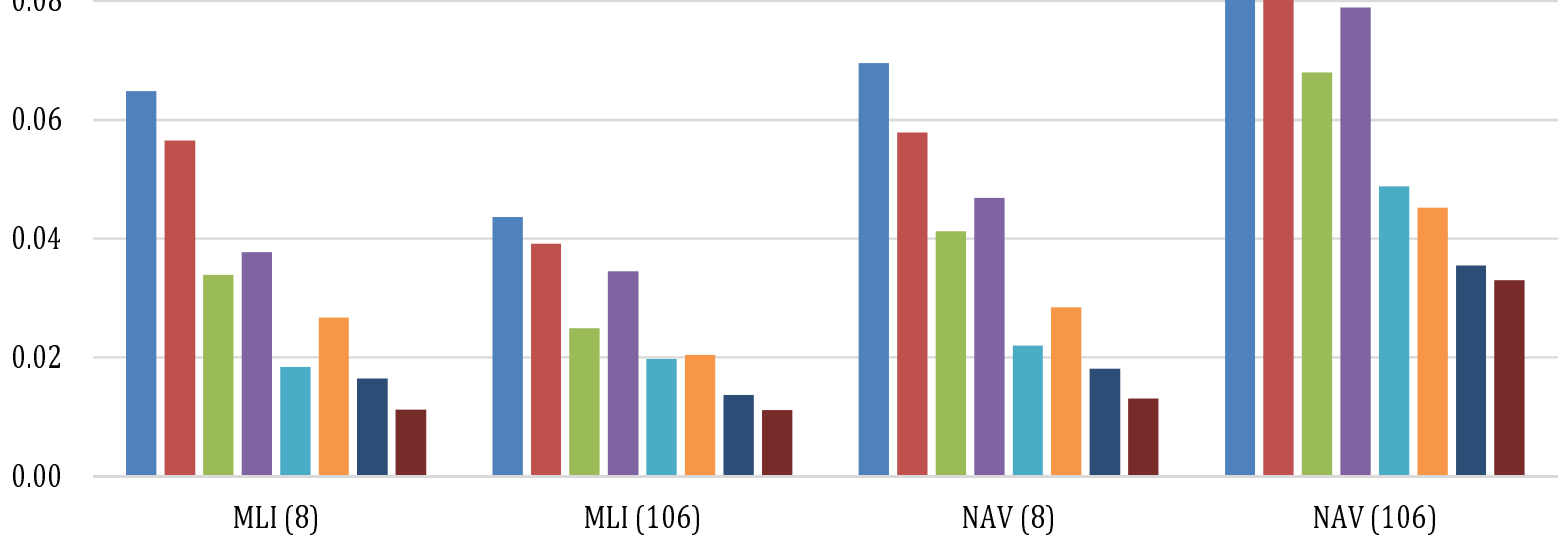

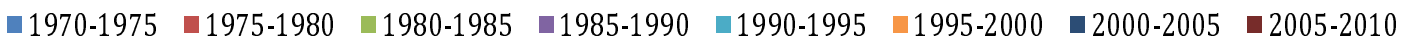

Note: From the author's calculation based on the JIP database 2014.

Figure 3: Structural change indices for annual and 5-year terms (capital stock) 
0.035

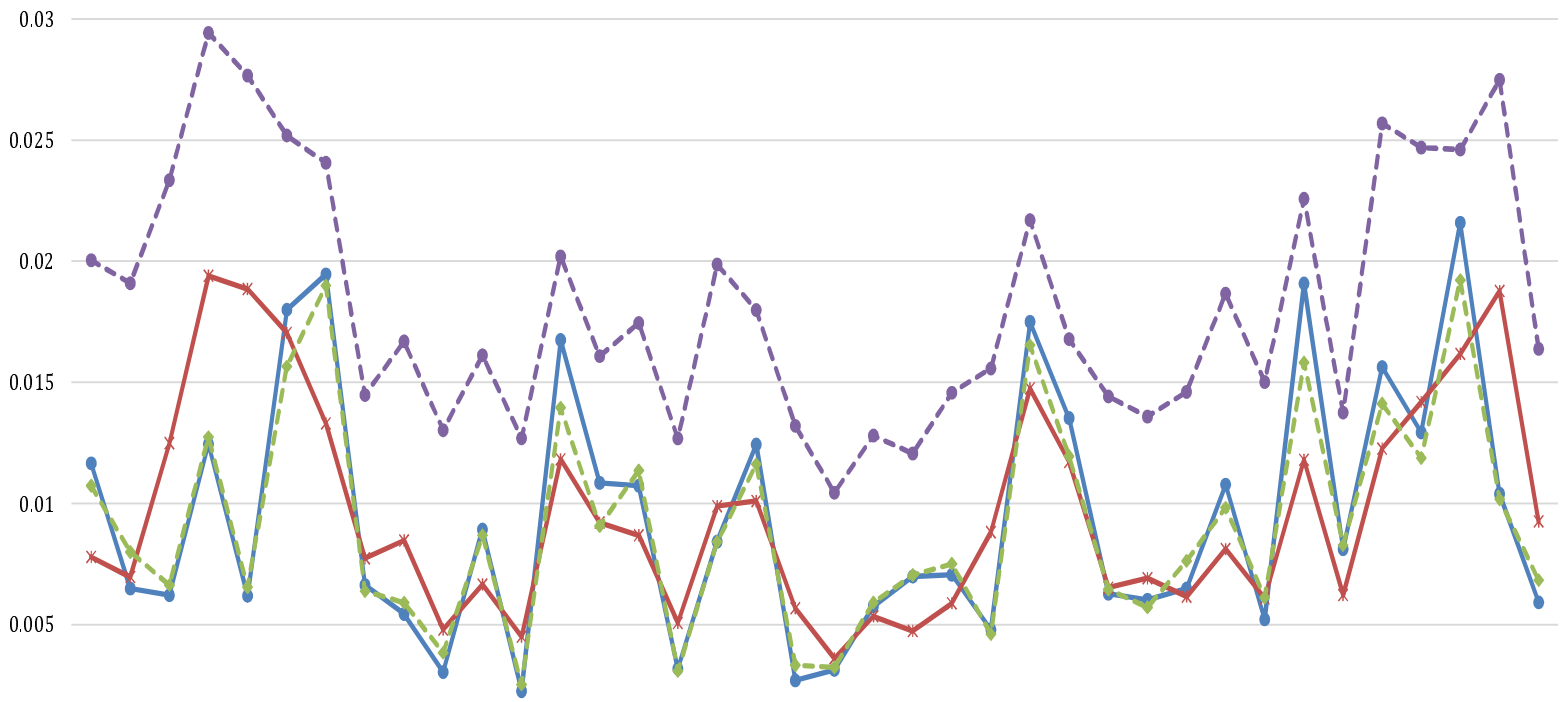

0

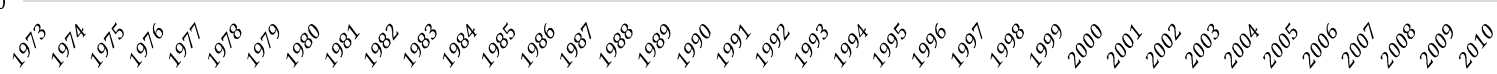

$\rightarrow \operatorname{MLI}(8) \quad$ *MLI(106) $\rightarrow-\operatorname{NAV}(8) \quad-\oplus-\operatorname{NAV}(106)$

SCI on capital-labour ratio for 5 years

0.14

0.12

0.10

0.08

0.04

0.02

0.00
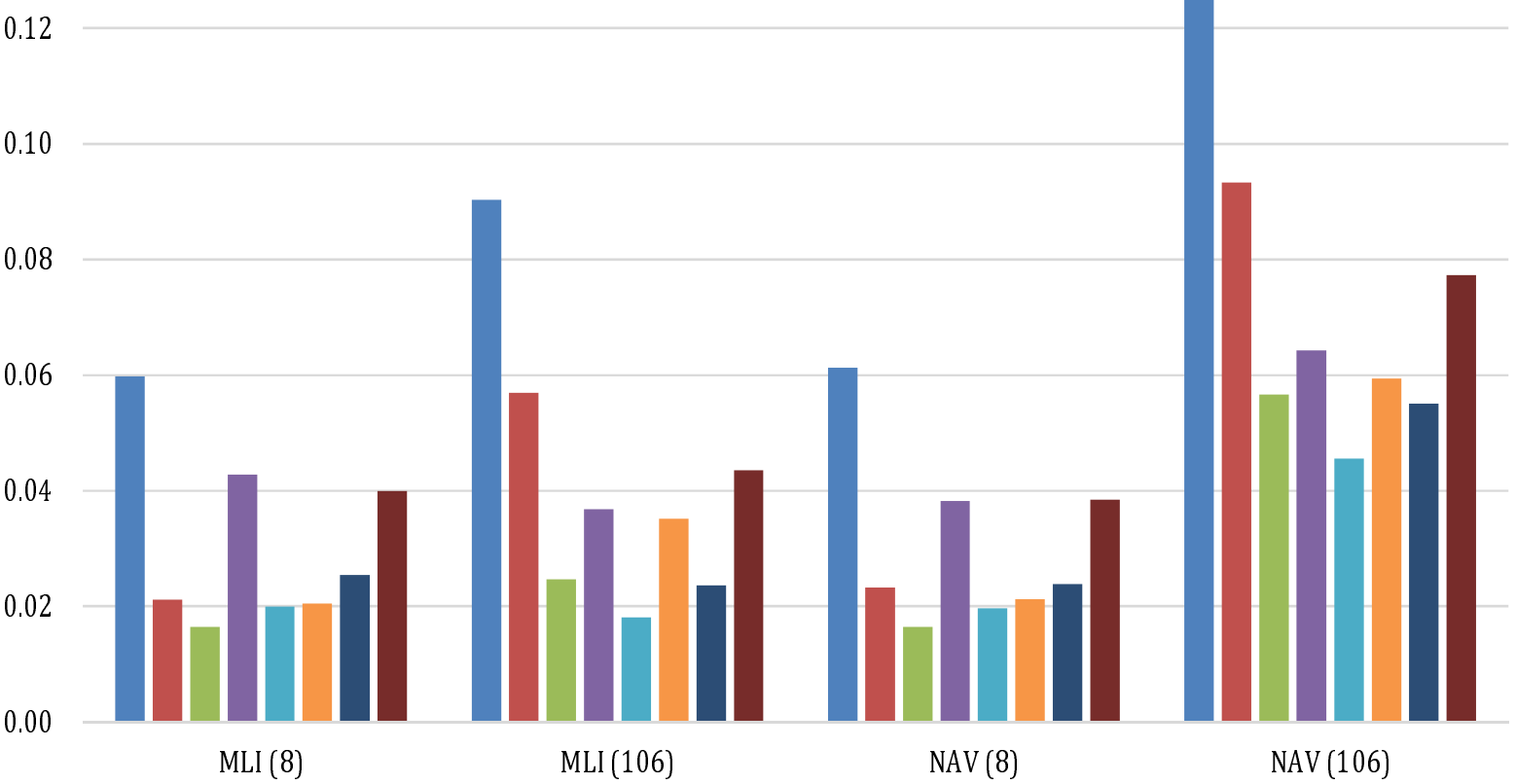

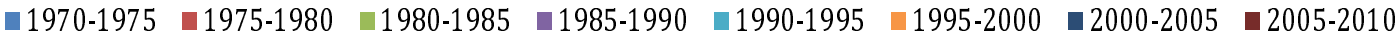

Note: From the author's calculation based on the JIP database 2014.

Figure 4: Structural change indices for annual and 5-year terms (capital-labour ratio) 
The structural change in capital-labour ratio reflects the structural change in production technology in terms of combination of capital and labour. It also reflects the industrial development in an economy. If an economy requires more capital equipment than labour, like during the development process of heavy industry, the ratio in the economy will rise. If an economy requires more labour than capital, like during tertiarization, the ratio in the economy will fall. Figure 4 shows the structural change indices for capital-labour ratio for both annual and 5-year terms. It is difficult to read a clear trend from the figure on annual and 5-year change because of its cyclical evolution. For a rough illustration, the structural change index for this variable in 1970 was relatively high, and the pace of change seems to have become faster again during the last 5 years of the 2000s.

What is relatively clear from the above figures are the long-run slowdown of structural change in capital stock and the recent increase in speed of structural change in value added. Prasad (1997) also uses the Lilien index to capture the degree of structural change in employment; it is documented that the Japanese economy has undergone gradual structural change in this term until the beginning of the 1990s, but there is no strong evidence of substantial increase in its speed since then. While this vision is partially true for employment, as figure 2 shows, the pace of structural change, especially in value added, in the Japanese economy, once again accelerated after the 2000s.

The structural change in these terms follows the change in both intra- and inter-sectoral economic performance. Through decomposition by log variance, we measure the change in sectoral dispersion of the level of value added and labour productivity for the eight sectors in intermediate 
classification. $^{7}$

Figure 5 shows the decomposition of the change in log variance of the value added for 5and 10-year terms. Except for 1985-1990, the change in log variance takes a negative value from 1970 to 2000 for 5-year term, indicating that the sectoral dispersion of economic performance for value added decreases. In contrast, since 2000 , the change in log variance began to take a positive sign, indicating that the sectoral dispersion of economic performance for value added increases. What is interesting is that the leading mechanisms change in these reduction and expansion of dispersion performance. In the process of reduction of change in log variance for value added, it is the within-group effect that was important. In contrast, in the process of increase of change in log variance since 2000, it is the between-group effect that was important. The figure on the change in log variance for 10-year terms also shows sectoral contribution to this value at the large classification. In terms of industry, the manufacture sector (L2) once again mostly led the increase and decrease of dispersion in value added through both effects. It contributed to

\footnotetext{
${ }^{7}$ The $\log$ variance measures the degree of inequality in economic outcomes, and it is often used in the analysis of income inequality. It also has an advantage in that we can understand the source of change in inequality by decomposing it into within-group effects (effect of dispersion within each group) and between-group effects (effect of dispersion between different groups). A positive value means that the dispersion is increasing, and a negative value means that it is decreasing. We apply this to measure the sectoral dispersion of value added and labour productivity. The method follows Uni (2011)'s analysis on wage inequality. The log variance of value added or productivity implies that of their logarithm value. When there are $m$ groups (eight sector in this case), the log variance of these terms is decomposed into within-group log variance and between-group log variance, as formally shown in the following equation:

$$
L V=\sum_{i=1}^{m} s_{i} L V_{i}+\sum_{i=1}^{m} s_{i}\left(\mu_{i}-\mu\right)^{2}
$$

where $L V$ is the log-variance of value added or labour productivity in aggregate term, $L V_{i}$ is that of the $i$ th sector, $s_{i}=n_{i} / n$ (where $n_{i}$ is the number of sub-sectors in the $i$ th sector) is the share of the $i$ th group, and $\mu_{i}$ is its mean of $\log$ of value added or productivity. From this, the change in the two different periods in log variance can be decomposed as follows:

$$
\Delta L V=\sum_{i=1}^{m} s_{i} \Delta L V_{i}+\sum_{i=1}^{m} s_{i} \Delta\left(\mu_{i}-\mu\right)^{2}
$$

The first term on the RHS is the contribution of change in the within-group dispersion, and the second term is the contribution of change in the between-group dispersion. Since the share of the $i$ th sector is constant over time in the JIP database 2014, the contributions of different log variance by group and the difference between the overall mean and the mean in each group do not appear in the current study.
} 
decrease in dispersion in value added especially in 1970-1980 and 1990-2000, and to increase in dispersion since 2000 .

Figure 6 shows the decomposition of the change in log variance for labour productivity for 5and 10-year terms. From the figure for 5-year terms, the change in log variance takes a negative value from 1970 to 1985 . During the next 15 years, the degree of dispersion seems to remain stable. Similar to the case of value added, the value of change in log variance has taken a positive sign since 2000, which means that the sectoral dispersion of economic performance on labour productivity increased. In the process of large convergence and dispersion of labour productivity, the within-group effect contributes more than the between-group effect in absolute value in most cases. The 10-year calculation indicates a decrease in labour productivity dispersion until 2000, but the convergence gradually slows down during the lost decade. Since 2000, the Japanese economy faces labour productivity dispersion at a high pace. The sectoral contribution to change in log variance in this figure shows that in terms of industry, the manufacture sector (L2) mostly leads the decrease in 1970-1980 and 1980-1990 and the increase since 2000.

The figures presented so far show an important hypothesis on the possibility of change in type of structural change for the past 40 years. The structural change until the 1990s in the Japanese economy accompanied a convergent process of sectoral economic performance as to the level of value added and labour productivity. The change in log variance of productivity and value added shows that the negative sign was more dominant until then. However, since 2000, some structural change indices such as for capital-labour ratio and value added accelerated, newly following the increasing dispersion of value added and labour productivity. Sectoral heterogeneity is apparent especially after 2000 through the lost decade. The hypothesis deduced from this section is that the structural change until 1990 might involve an even growth process, but that at high pace in the 2000s through the lost decade might involve an uneven growth process. The next section examines this hypothesis in terms of distribution of sectoral contribution to economic growth.

\subsection{Economic growth and distribution of sectoral contribution}

The previous sections measured the structural change in inputs and output for the past 40 years in the Japanese economy. They also showed that sectoral dispersion decreased until 1990 but has increased since 2000. This section focuses on the relationship between sectoral performance and overall economic growth. It attempts to show how the performance of each sector contributes to 
0.60

0.40

0.20

0.00

$1970-1975 \quad 1975-1980 \quad 1980-1985 \quad 1985-1990 \quad 1990-1995 \quad 1995-2000 \quad 2000-2005 \quad 2005-2010$

$-0.20$

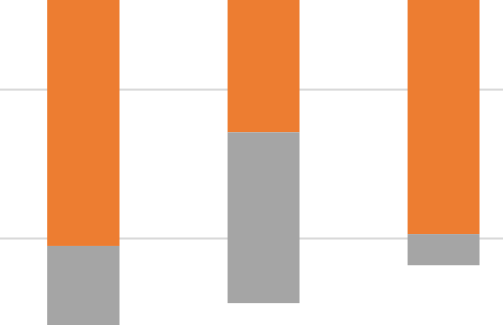

$-0.60$

within-effects $\square$ between-effects

Change in LV on value added for 10 years

1.00

0.80

0.60

0.40

0.20

0.00

$-0.20$

$1970-1980$
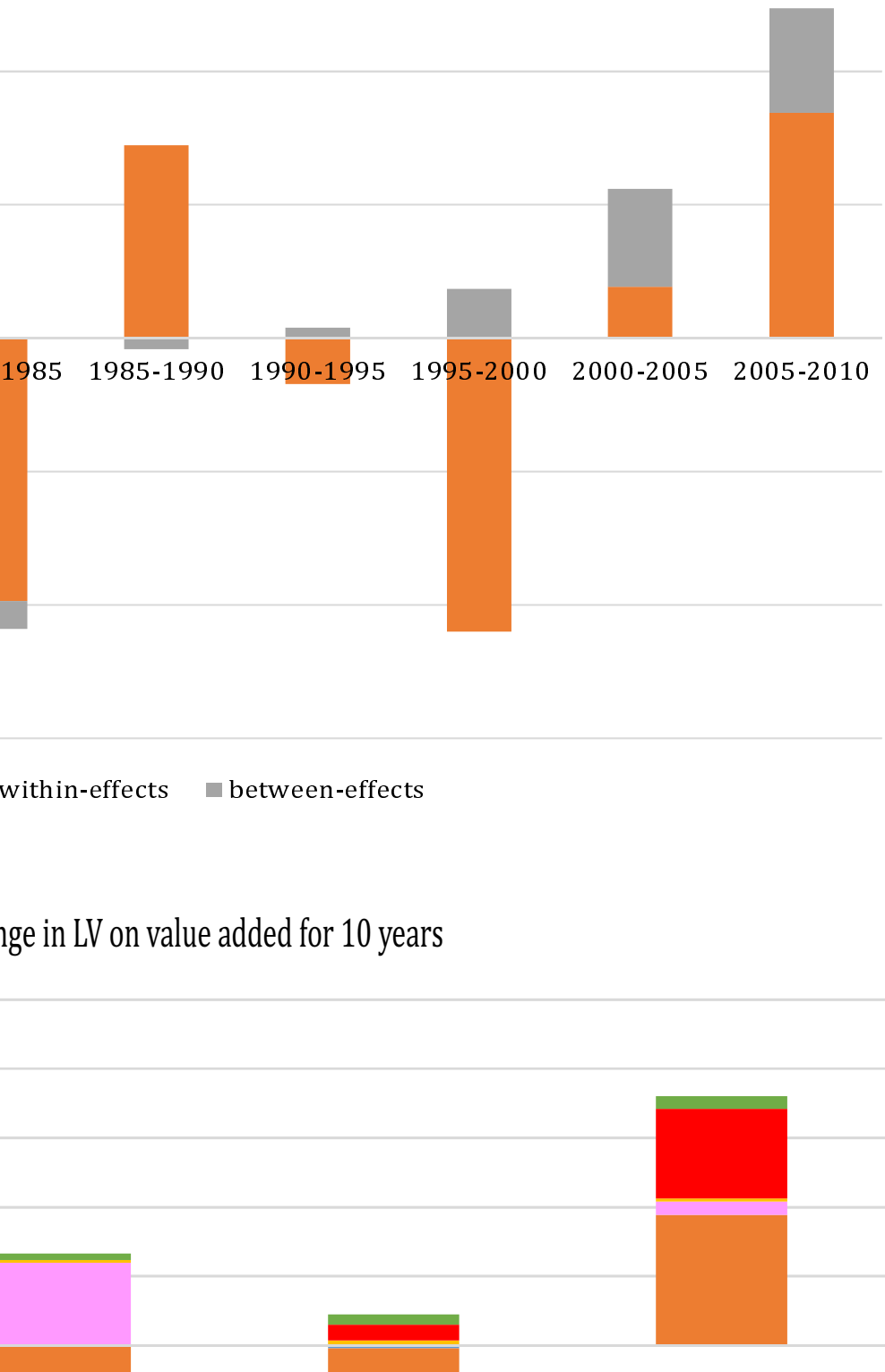

$-0.40$

$-0.60$

$-0.80$

$-1.00$

$-1.20$

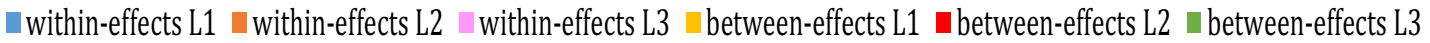

Note: From the author's calculation based on the JIP database 2014.

Figure 5: Decomposition of change in value added dispersion 
Change in LV on labour productivity for 5 years

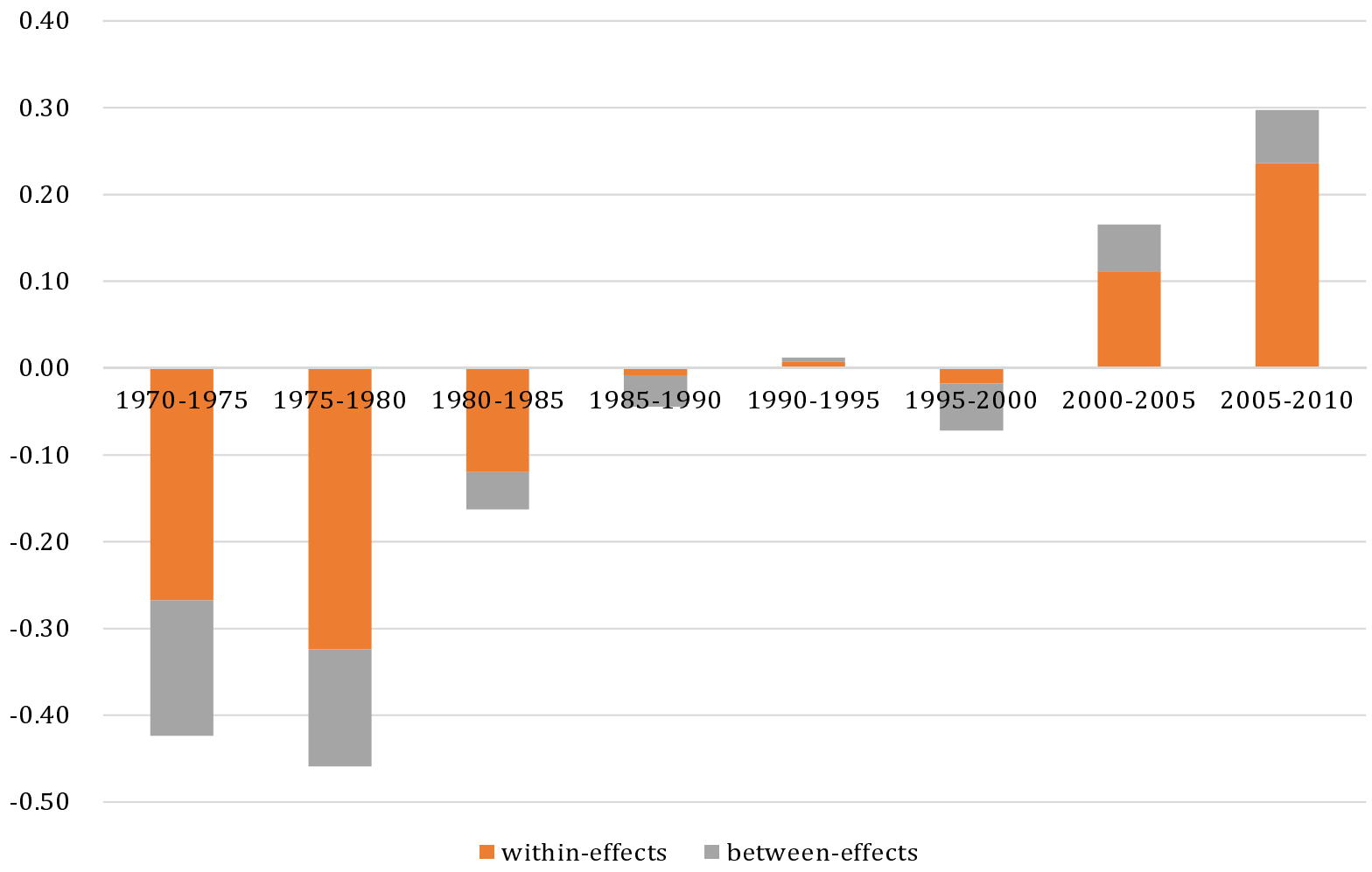

Change in LV on labour productivity for 10 years

0.60

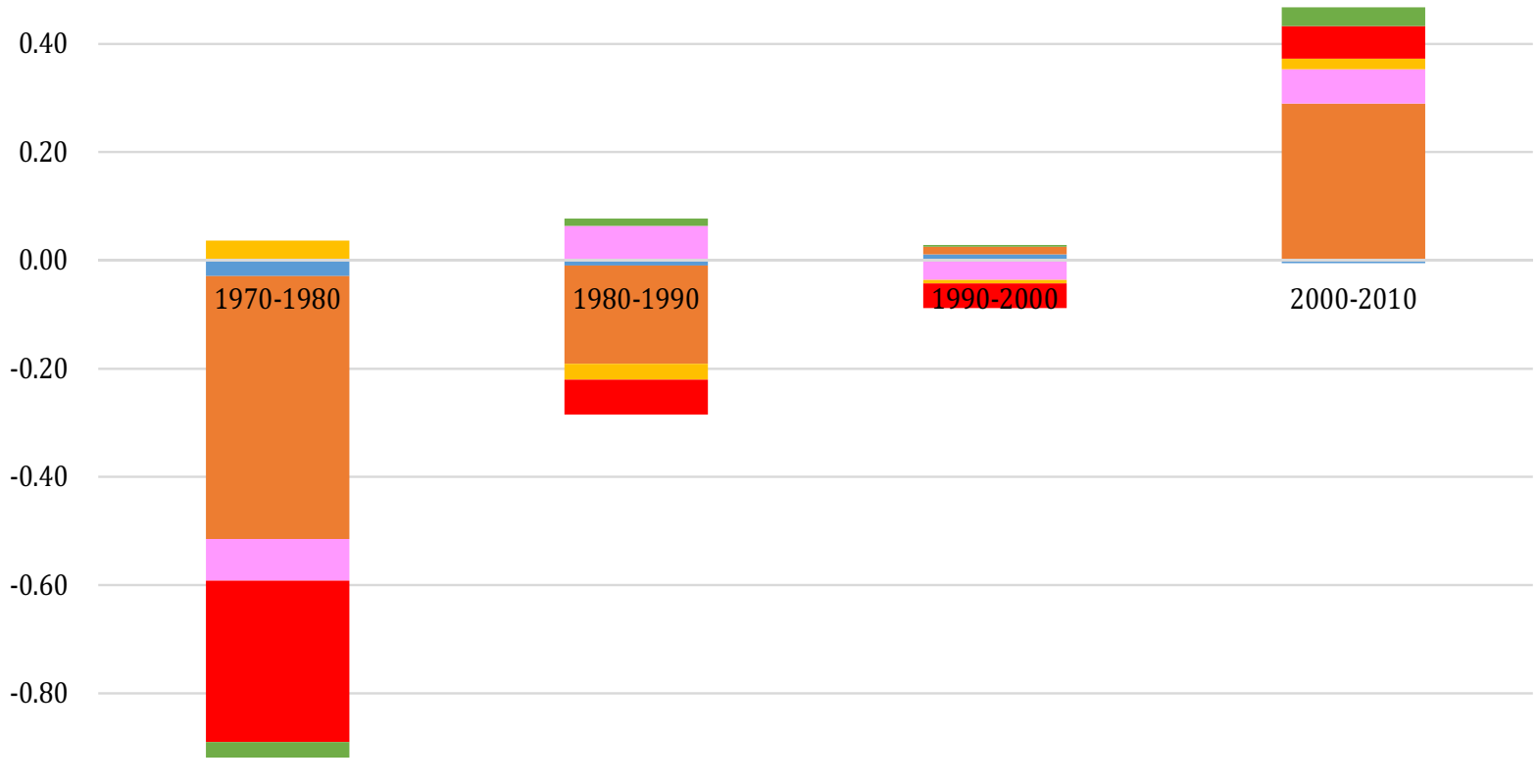

$-1.00$

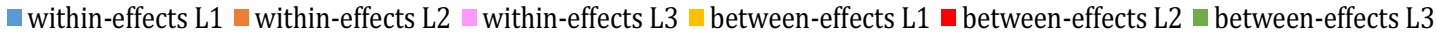

Note: From the author's calculation based on the JIP database 2014.

Figure 6: Decomposition of change in labour productivity dispersion 
the aggregate economic growth in value added and labour productivity.

Herberger (1998)'s sunrise-sunset diagram is useful to show the distribution of contribution of the individual 106 sectors to economics growth in value added and labour productivity. From this diagram, we plot the cumulative share of sectoral value added in total value added in the horizontal axis and the cumulative contribution to value added growth in the vertical axis in figures 6 to 10 by dividing each decade into 5-year terms. The upper part of the figures represents the growth in value added. The vertical axes display the cumulative sectoral contributions to aggregate growth in value added, while the horizontal axes depict the cumulative share of sectoral output in total value added. The slope of the curve reflects the product of each sector's share and the growth rate of the variable. Consequently, the slope is steeper for the sector with high growth rate. The sectors are lined up by descending order of value added contribution. The lower part of the figures represents the cumulative contribution to labour productivity growth in relation to the cumulative share of sectoral man-hours in total man-hours. The sectors are lined up by descending order of labour productivity contribution. ${ }^{8}$

The sunrise-sunset diagram contains important information on the growth in value added and labour productivity. It shows the sectoral distribution that positively or negatively contributes to the aggregate growth in labour productivity and value added. It also shows the maximum and average growth rates of these variables. The average rate is shown at the right-hand side of the distribution (i.e., the sum of all contributions), whereas the maximum growth rate is shown at the top of the curve (i.e., the sum of positive contributions). Consequently, there is an overshooting configuration of the growth rate, indicating both positively and negatively contributing sectors.

\footnotetext{
${ }^{8}$ These plots are modified illustrations of Herberger (1998). With regard to labour productivity decomposition, the current method also follows Syrquin (1988). Since the aggregate labour productivity per man-hour $y$ is defined by $y=\sum y_{i} s_{L, i}$. where $y_{i}$ is the sectoral labour productivity per man-hour and $s_{L, i}$ the sectoral share of man-hours. The increment of labour productivity is as follows:

$$
\Delta y=\sum_{i} \Delta y_{i} s_{L, i}+\sum_{i} y_{i} \Delta s_{L, i}
$$

The growth rate of labour productivity at the macroeconomic level is obtained by dividing both sides by $y$, which is

$$
\frac{\Delta y}{y}=\sum_{i} s_{L, i}\left(\frac{\Delta y_{i}}{y}+\frac{\Delta s_{L, i}}{s_{L}} \cdot \frac{y_{i}}{y}\right)
$$

where the first term in parenthesis represents the 'within effect' and the second term represents the 'between-effect' (Baily et al. (1992); Krüger (2008b)). Therefore, the aggregate productivity growth can be decomposed into withinsector growth in labour productivity and sectoral shift in man-hour share.
} 
This configuration becomes clear as the negative sectoral contribution increases. ${ }^{9}$

Figure 7 shows the sectoral value added and productivity growth contribution in 1970-1975 and 1975-1980 for the economy as a whole. Three observations can be made with regard to the growth in value added. The first is about the distribution of positively and negatively contributing sectors. The figure shows that most sectors positively contributed to increase the growth in value added; $78.0 \%$ of the total sectors positively contributed to value added growth, whereas the share of sectors negatively contributing was only $22.0 \%$ in the first half of the 1970 s. The share of positively contributing sectors increased to $85.2 \%$ in the last half of the 1970s. The second observation is about the maximum growth rate. The total contribution of all sectors positively contributing reached $4.2 \%$ of the annual growth rate, whereas the $22.0 \%$ negatively contributing sectors decreased the value added growth rate by $1.1 \%$ in 1970-1975. The same figure for 19751980 reports that the share of positive contribution reached $4.8 \%$ of the annual growth rate, whereas the $14.8 \%$ negatively contributing sectors decreased the growth rate by $1.5 \%$. The last observation is about the average growth rate and its relation with the distribution of sectors. The average annual growth rates of value added in the economy for the first and second 5 years as a whole were $3.1 \%$ and $3.4 \%$, which are equal to the total positive contribution by the top $50.7 \%$ and $34 \%$ of all sectors, respectively.

Figure 7 also shows the distribution of sectoral contribution to labour productivity growth in 1970-1975 and 1975-1980 for the economy as a whole. First, most sectors positively contributed to the growth in labour productivity: $82.9 \%$ and $69.5 \%$ of all sectors positively contributed to growth in labour productivity in 1970-1975 and 1975-1980, respectively. Second, their maximum growth rates reached $4.6 \%$ and $3.8 \%$. Finally, the average annual growth rates in the economy as a whole were $3.4 \%$ and $2.3 \%$ in the first and second 5 years, which are equal to the total positive contribution by the top $41.1 \%$ and $33.3 \%$ of all sectors, respectively.

Similarly, figures 8-10 show the sectoral contribution to growth in value added and productivity after 1980. A comparison of the diagrams for two growth terms over 40 years shows the following characteristics in terms of both growth rate and sectoral distribution. The most striking change is the major transformation in sectoral contribution pattern on growth in value added and productivity before and after 1990 . In the 1970 s and 1980 s, almost $80-85 \%$ of the total sectors

\footnotetext{
${ }^{9}$ Inklaar and Timmer (2007) introduced summary measures for Herberger diagram that indicate the pervasiveness of growth pattern. Their study finds growth of TFP is much more localized or mushroom-like.
} 
Sectoral contribution to value added growth: the $1970 \mathrm{~s}$

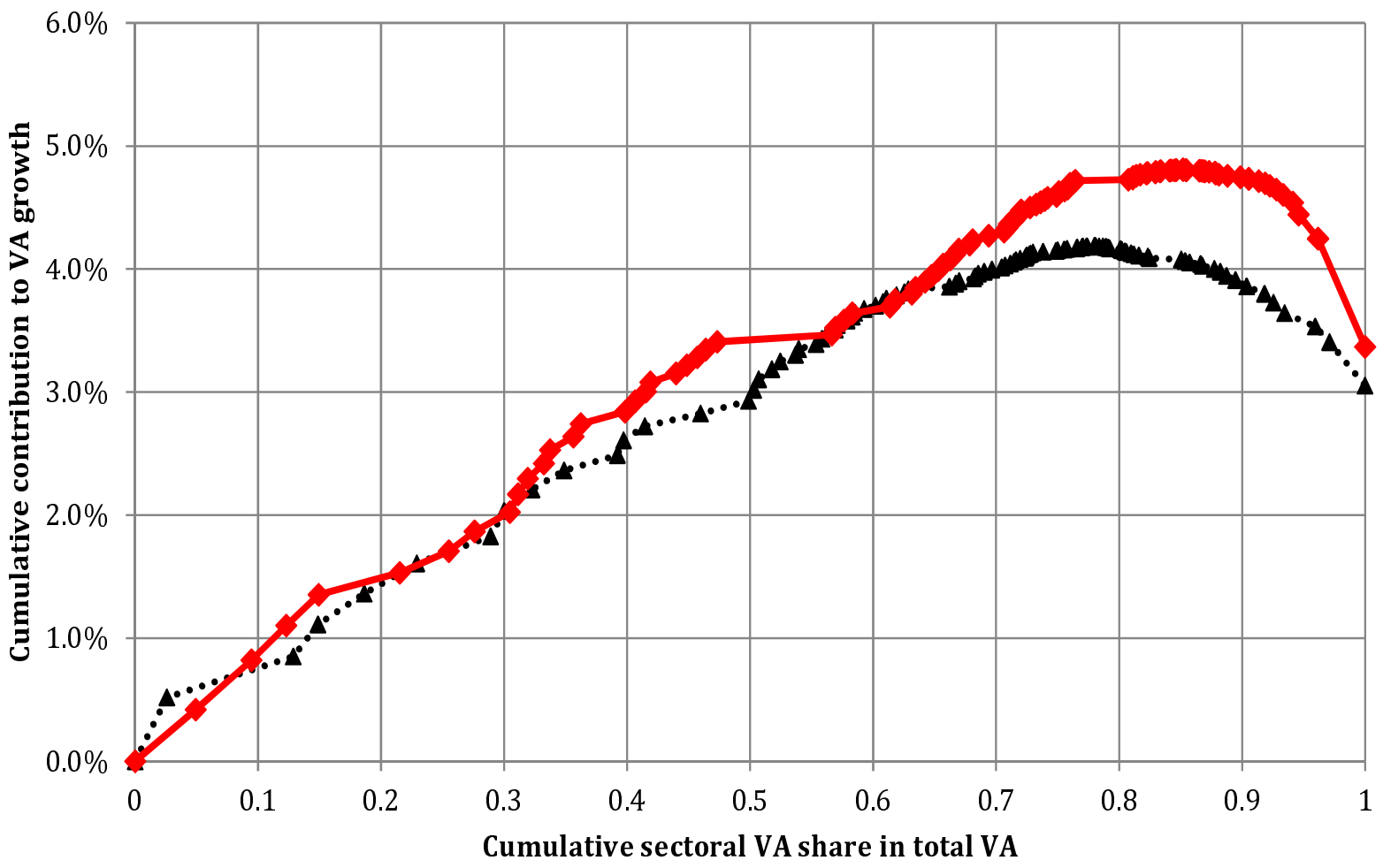

Sectoral contribution to LP growth: the1970s

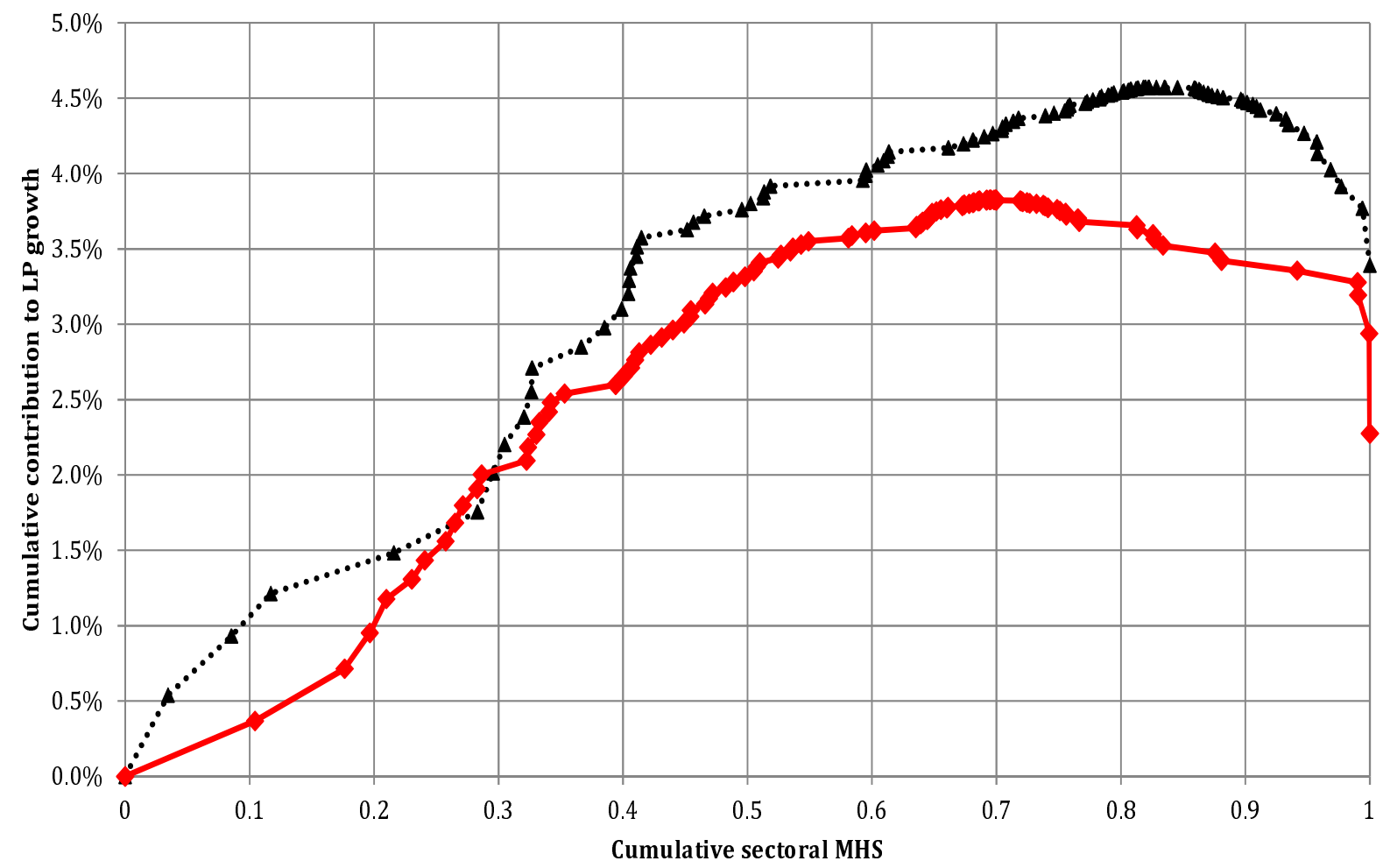

Note: The black dotted line with triangle marker represents the distribution in 1970-1975 (the first half of the period). The red solid line with square marker represents the distribution in 1975-1980 (the latter half of the period). This representation is the same for figures $8-10$. VA is value added, LP is labour productivity, and MHS is sectoral man-hour share.

Figure 7: Cumulative contribution of inchestries to VA and LP growth (1970-1980) 
Sectoral contribution to value added growth: the 1980s

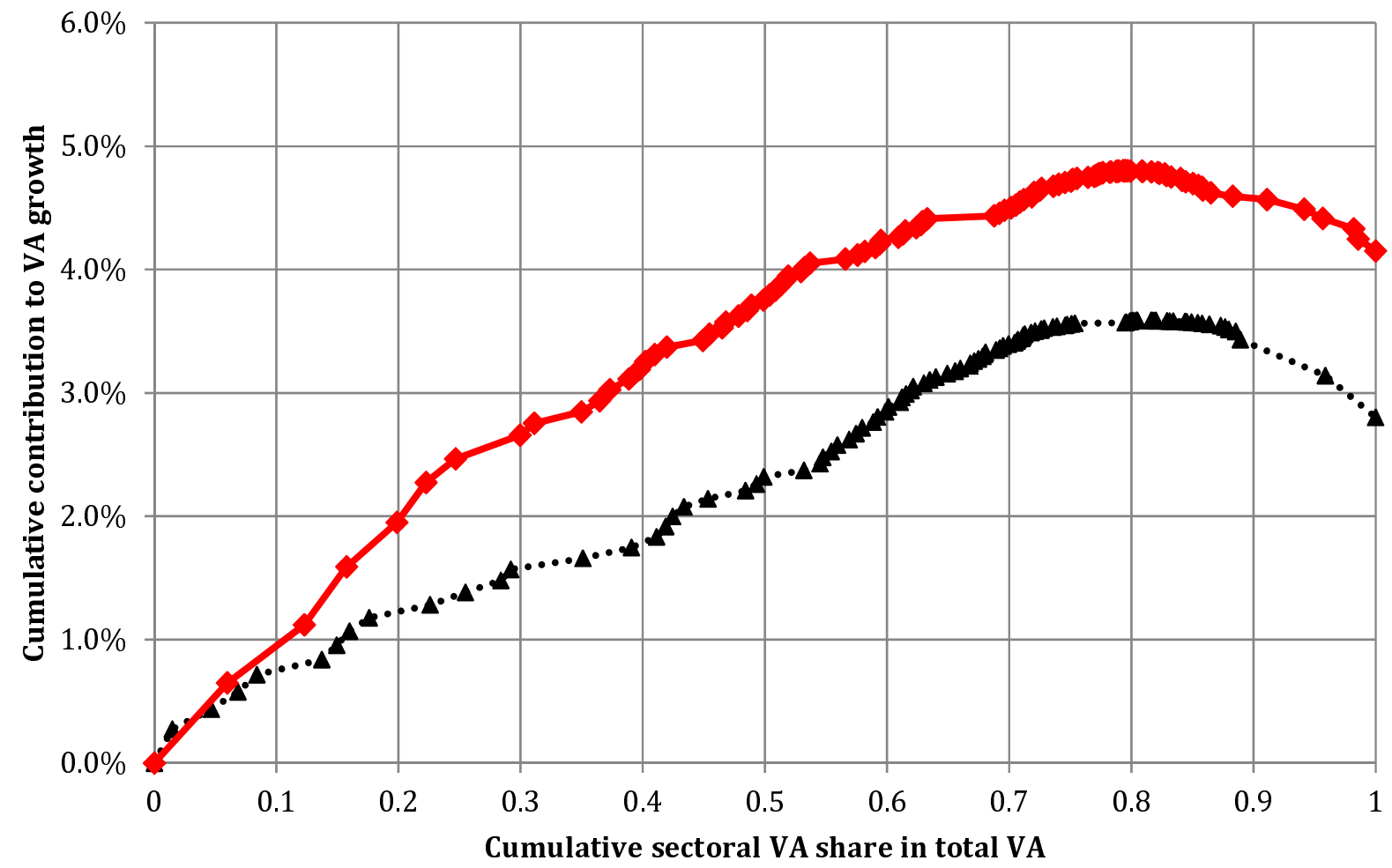

Sectoral contribution to LP growth: the 1980s

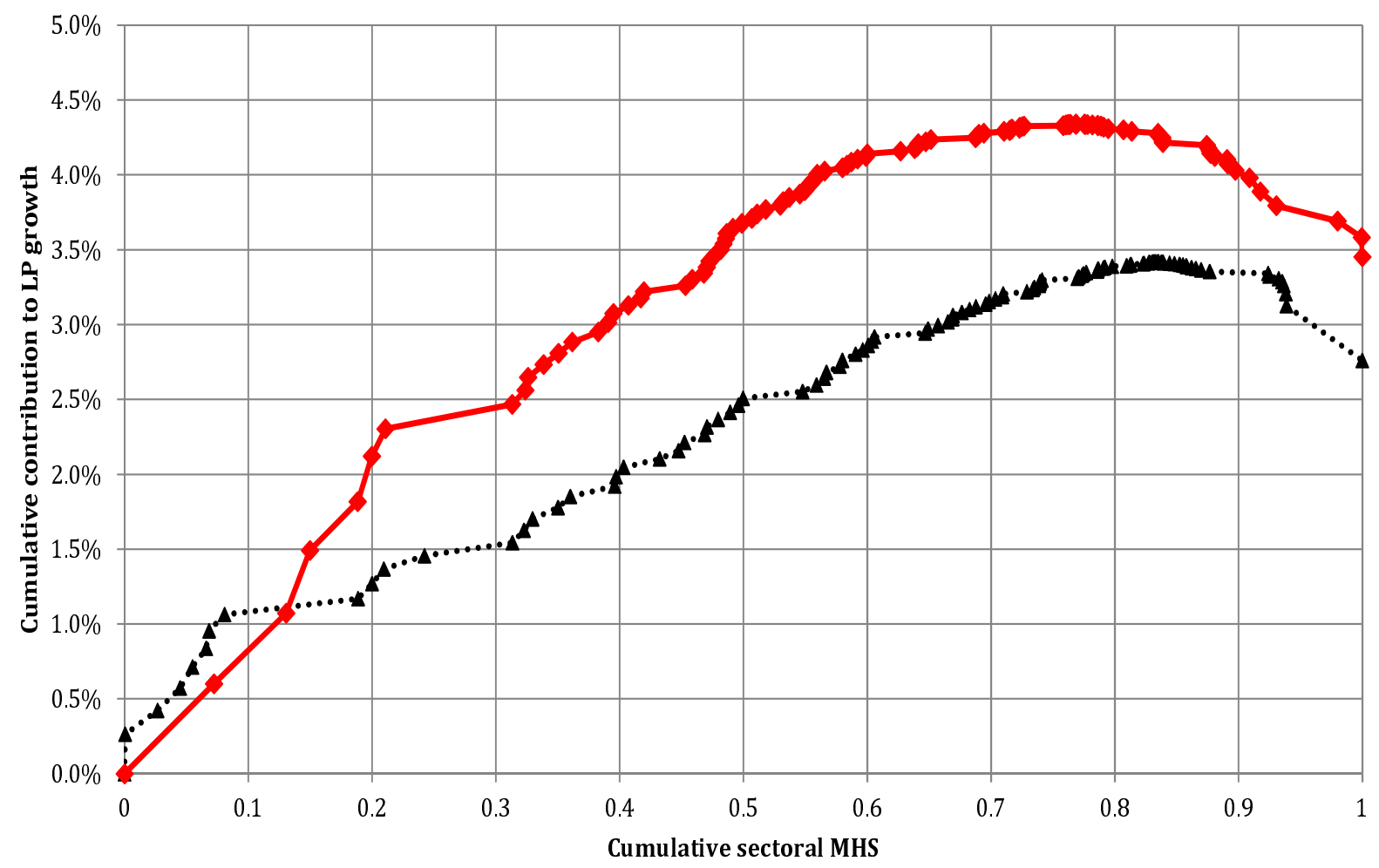

Figure 8: Cumulative contribution of industries to VA and LP growth (1980-1990) 
Sectoral contribution to value added growth: the 1990s

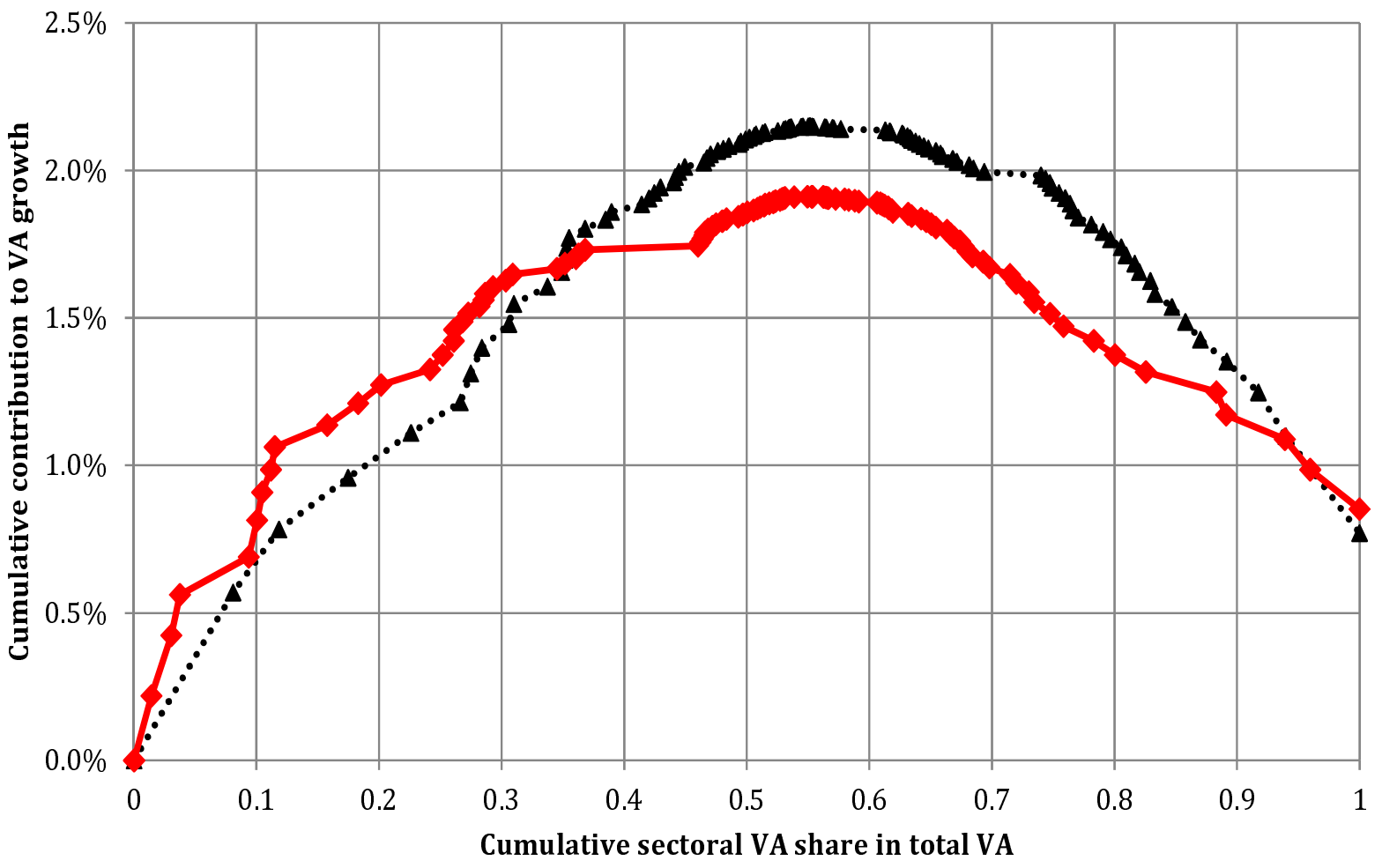

Sectoral contribution to LP growth: the 1990s

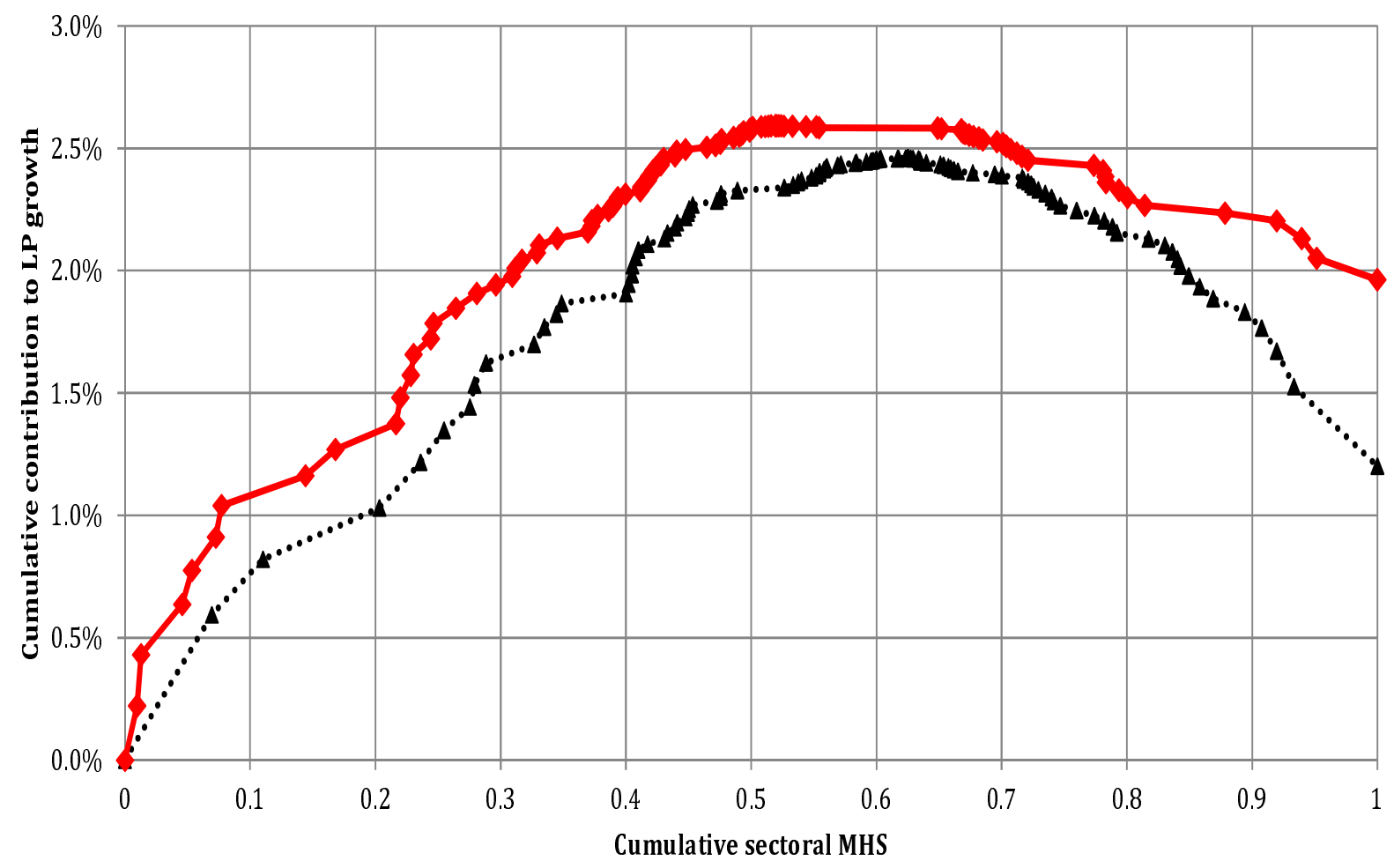

Figure 9: Cumulative contribution of industries to VA and LP growth (1990-2000) 
Sectoral contribution to value added growth: the 2000s

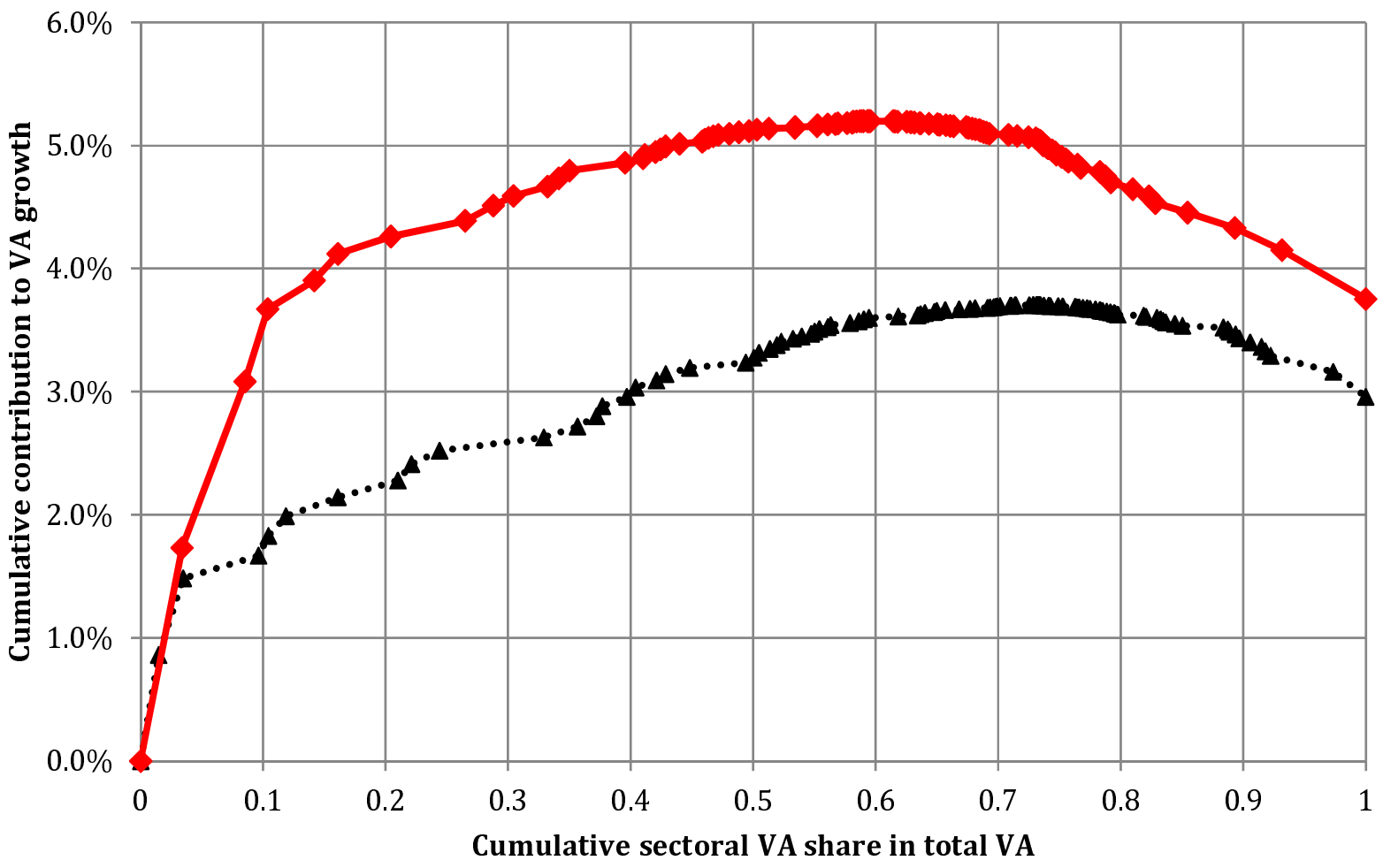

Sectoral contribution to LP growth: the 2000s

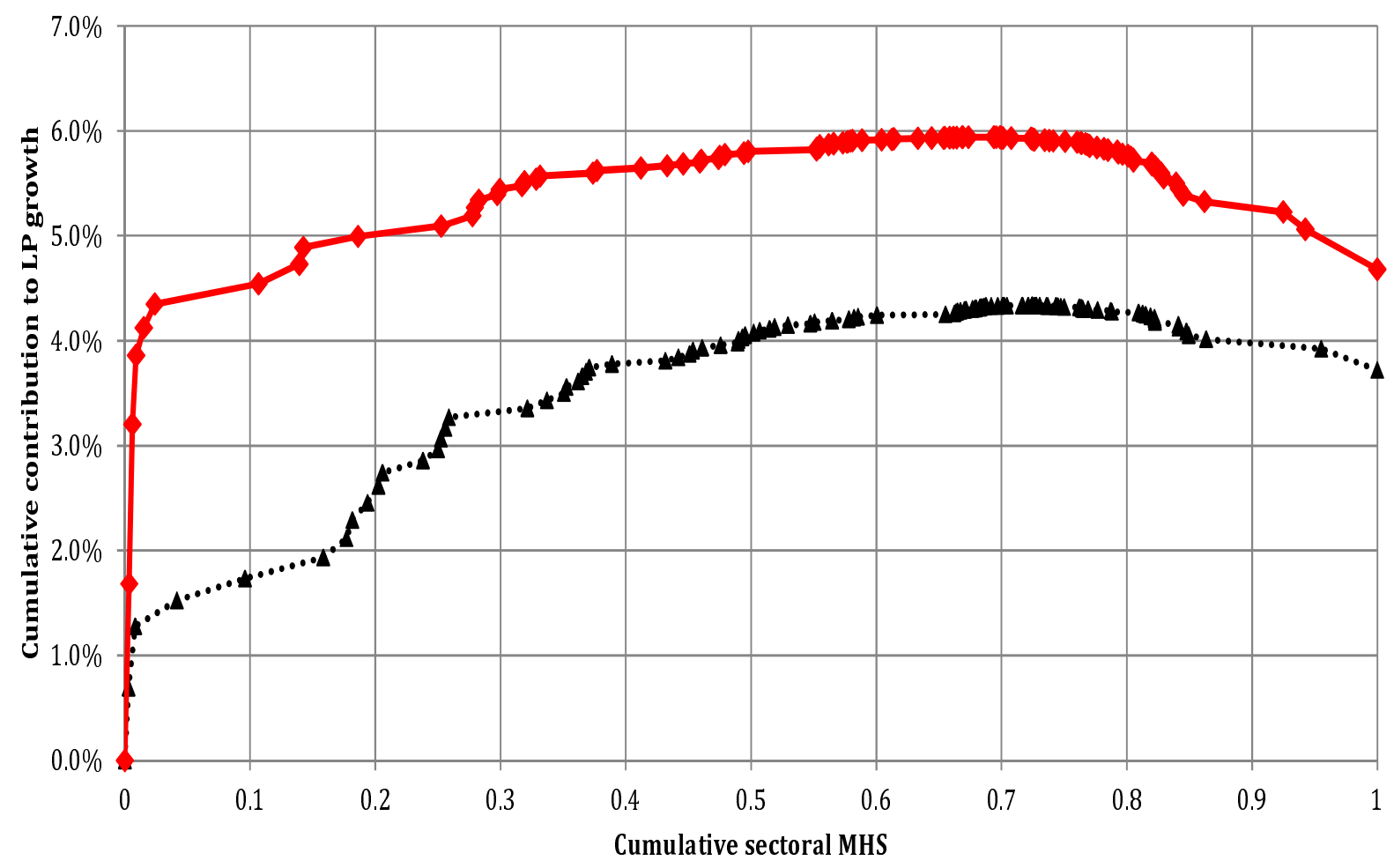

Figure 10: Cumulative contribution of industries to VA and LP growth (2000-2010) 
positively contributed to value added growth, whose maximum rate reached the annual average of $3.7-4.2 \%$ for 10 years. ${ }^{10}$ The share of positively contributing sectors increased from 75.6 $\%$ in the 1970 s to $84.9 \%$ in the 1980 s of the total sectors for productivity growth, although the maximum rate for these periods slightly went down from $4.04 \%$ to $3.62 \%$. However, the share of sectors positively contributing to both variables in the total economy has decreased since the 1990s. The share of sectors positively contributing to growth in value added largely decreased to $55.4 \%$ in the $1990 \mathrm{~s}$. Moreover, both the average and maximum growth rates in this period sharply fell to $0.8 \%$ and $1.7 \%$, respectively. Although both the average and maximum growth rates of value added recovered to $3.5 \%$ and $4.4 \%$, respectively, in the $2000 \mathrm{~s}$, the share of positively contributing sectors remains $62.3 \%$, which is still lower than the share 20 years ago.

The sectoral distribution of labour productivity follows an evolution similar to the growth in value added. The share of sectors positively contributing to growth in labour productivity largely decreased from $84.9 \%$ in the 1980 s to $68.0 \%$ in the 1990 s to $63.7 \%$ in the 2000 s. Therefore, the average and maximum growth rates in the 1990s sharply fell to $2.4 \%$ and $1.6 \%$, respectively. Although both the average and maximum growth rates of value added recovered to $4.6 \%$ and $5.3 \%$, respectively, since 2000 , the cumulative share of positively contributing sectors decreased since the 1980s.

What is also striking is that the economic growth since 2000 is mostly led by limited sectors. The slope is relatively steeper for the sector with high growth rate in these figures, and figure 10 for the latter half of the 2000s indicates the top three sectors (No. 47, 48, and 51) have quite steep slopes. These sectors are classified as the export-core sectors (M2) in the intermediate classification. Boyer et al. (2011) and Uemura and Tahara (2014) characterize the Japanese growth regime since 2000 as export-led. It is also possible to understand this character from these sunrise-sunset diagrams.

In sum, the sectoral distribution of growth in value added and labour productivity was relatively uniform before 1990, and the growth was led by all sectors. However, the distribution has generally shifted leftward since 1990, leading to a sharp overshooting configuration in growth in these terms. To use Herberger (1998)'s metaphor, the growth before 1990 followed a yeast-type process (overall growth), whereas that after 1990 followed a mushroom-type process (uneven

\footnotetext{
${ }^{10}$ The annual average growth rate and sectoral share for 10 years for each term are also calculated in a similar manner for 5 years. We do not report the detail in this paper due to space limitations.
} 
growth). ${ }^{11}$ In the mushroom-type growth process, like after 1990, there appear two types of sectors. That is, there are negatively contributing sectors as well as positively contributing sectors in an economy. The economic growth was intensively led by limited sectors, while others dragged growth. Therefore, even if the Japanese economy grows or stagnates on average, the process is not uniform but uneven among heterogeneous sectors.

Last but not least, our distribution analysis is also related to what is stated in the previous section. The yeast-type growth process before 1990 in the Japanese economy involves a decrease in sectoral dispersion in value added and labour productivity. On the contrary, the mushroomtype growth process after 1990 led to increase in sectoral dispersion in these terms.

\subsection{Durability of leading and stagnating sectors}

As the previous section shows, the leading sectors positively and strongly contribute to growth in value added and labour productivity, whereas the stagnating sectors negatively contribute to growth. To shed more light on the relationship between structural change and economic growth, we need to examine whether the leading (stagnating) sectors are still the leading (stagnating) ones over time.

Table 2 shows the Spearman correlation coefficient between periods pertaining to the sectoral order of contribution to growth in value added and labour productivity. Using this, we attempt to measure the durability of the contribution of each sector. If the leading (stagnating) sectors are still leading (stagnating) ones over time, the correlation coefficient should take a high positive value. On the contrary, if the leading (stagnating) sectors shift to stagnating (leading) ones over time, it should take a high negative value. Moreover, if the composition of the sectoral order almost changes over time, it should take an insignificant value close to zero.

First, the upper part of the table shows the durability of the sectoral order of contribution to growth in value added. Specifically, the sectoral order of contribution before 1990 does not seem to be effective over time. Although there is a temporal increase in positive correlation in

\footnotetext{
${ }^{11}$ In his original TFP analysis, Herberger (1998) explained the relationship between the distribution of sectoral performance and macroeconomic outcome as 'yeast versus mushrooms'. This is a metaphor used for economic growth process, and the 'yeast' process means that each industrial sector evenly and mostly contributes to the TFP growth process, whereas the 'mushrooms' process indicates the TFP growth process in which only a small share of industry contributes intensively. Inklaar and Timmer (2007) and Timmer et al. (2013) are applications of this metaphor for industry pattern of growth.
} 
Table 2: Spearman's correlation coefficient on order of contribution

\begin{tabular}{lllllllll}
\hline \hline VA growth & $1970-1975$ & $1975-1980$ & $1980-1985$ & $1985-1990$ & $1990-1995$ & $1995-2000$ & $2000-2005$ & $2005-2010$ \\
\hline $1970-1975$ & 1.000 & & & & & & & \\
$1975-1980$ & $0.289^{* * *}$ & 1.000 & & & & & & \\
$1980-1985$ & $0.329^{* * *}$ & $0.451^{* * *}$ & 1.000 & & & & & \\
$1985-1990$ & 0.157 & $0.385^{* * *}$ & $0.303^{* * *}$ & 1.000 & & & & \\
$1990-1995$ & $0.331^{* * *}$ & 0.007 & $0.193^{* *}$ & 0.008 & 1.000 & & & \\
$1995-2000$ & -0.025 & -0.044 & 0.089 & 0.057 & $0.250^{* * *}$ & 1.000 & & \\
$2000-2005$ & 0.091 & $0.262^{* * *}$ & $0.243^{* *}$ & $0.291^{* * *}$ & $0.229^{* *}$ & $0.407^{* * *}$ & 1.000 & \\
$2005-2010$ & -0.040 & 0.000 & -0.030 & -0.079 & $0.287^{* * *}$ & $0.309^{* * *}$ & $0.326^{* * *}$ & 1.000 \\
\hline \hline LP growth & $1970-1975$ & $1975-1980$ & $1980-1985$ & $1985-1990$ & $1990-1995$ & $1995-2000$ & $2000-2005$ & $2005-2010$ \\
\hline $1970-1975$ & 1.000 & & & & & & & \\
$1975-1980$ & 0.181 & 1.000 & & & & & & \\
$1980-1985$ & $0.293^{* * *}$ & $0.481^{* * *}$ & 1.000 & & & & & \\
$1985-1990$ & 0.112 & $0.277^{* * *}$ & $0.235^{* *}$ & 1.000 & & & \\
$1990-1995$ & $0.384^{* * *}$ & 0.083 & $0.226^{* *}$ & 0.054 & 1.000 & & & \\
$1995-2000$ & 0.014 & 0.170 & $0.208^{* *}$ & 0.152 & $0.238^{* *}$ & 1.000 & & \\
$2000-2005$ & 0.181 & $0.327^{* * *}$ & $0.351^{* * *}$ & $0.326^{* * *}$ & $0.246^{* *}$ & $0.480^{* * *}$ & 1.000 & \\
$2005-2010$ & -0.008 & 0.099 & 0.055 & -0.055 & $0.291^{* * *}$ & $0.294^{* * *}$ & $0.331^{* * *}$ & 1.000 \\
\hline \hline
\end{tabular}

Note: By author's calculation on the basis of JIP 2014. Significance at $1 \%$ and at $5 \%$ is denoted by ${ }^{* * *}$ and ${ }^{* *}$, repsectively.

2000-2005, the leading and stagnating order before 1990 is generally not sustained in the long run. For example, the correlation between the order in 1975-1980 and that in the 1980s takes a high value, but it decreases with the order of the 1990s and the 2000s. Generally, the durability of the contribution order of each sector to growth in value added works only in the short run, meaning that the composition of the leading (stagnating) sectors almost changes in the long run.

Second, the lower part of the table shows the durability of the sectoral order of contribution to growth in labour productivity. This table shows a configuration similar to that of value added growth. Except for a temporal increase in positive correlation in 2000-2005, the leading and stagnating order before 1990 is not durable in the long run. The sectoral orders of contribution especially before 1980 do not endure over time, as the order correlation coefficient between these periods with the order after the 1990s and the 2000s generally decreases and is not significant. Thus, the composition of the leading (stagnating) sectors of labour productivity almost changes in the long run as well.

The size of the order correlation in most cases is about $30 \%$ at most, even when it is strong. 
Such a case applies only in the short run of 5 or 10 years. However, it is hard to expect the same composition of leading and stagnating sectors to continue in the long run.

Table 3 presents the sectoral distribution of the order for every 10 years on the basis of intermediate classification. With regard to agriculture (M1, L1), whose share in the total sectors is small and $5.66 \%$ (respectively), the order of contribution to growth in value added is ranged in the lower rank for almost 40 years. Among the manufacturing sectors, other manufacturing (M3) occupies $34.91 \%$ of the total sectoral share, which is the largest share in the economy. However, only a small part of this sector enters the top 25 percentile of the value added growth. At most, $7.55 \%$ of this sector in the whole economy (21.62\% within this sector) is ranked in the top 25 percentile in the $1980 \mathrm{~s}$. In contrast, this $14.15 \%$ in total sectors $(40.54 \%$ within this sector) is ranked in the bottom 25 percentile in the 2000s. On the other hand, export-core manufacturing (M2) led the growth in value added for these 20 years. The share of this sector is $15.09 \%$ of all sectors; $4.72 \%$ (31.25\% within this sector) contributed to growth as the top $25 \%$ in $1990 \mathrm{~s}$, and this rose to $9.43 \%$ (62.50\% within this sector) in the 2000s. Among the services sectors, business-related services in a narrow sense (M5) and public services (M8) relatively contributed to value added growth. Almost half of these services sectors contributed to growth in value added for the past 40 years.

The lower part of table 3 presents a similar configuration about the order of sectoral contribution of labour productivity. The difference between the orders of sectoral contribution to value added and labour productivity growth if any is quite small at intermediate classification. Briefly summarizing, first, the agricultural sector mostly ranks in the bottom half of the order of contribution to labour productivity. Second, most part of the export-core manufacturing leads to an increase in labour productivity. Third, most services sectors contributed to labour productivity growth. The share of services in the top half percentile to contribution is higher than that in the bottom half, as the number in L3 indicates. 
A comparison at the large classification shows that leading sectors for both variables change over time especially among the manufacturing (L2) and services (L3) sectors. The sectoral share in the top $25 \%$ of L2 and L3 changes in a fluctuating manner. For an example of value added growth, from the 1970 s to the 1980 s, the share of L2 in this range increased to $13.21 \%$ while that of L3 decreased to $12.26 \%$. From the 1980s to the 1990s, the share of L2 in this range decreased to $7.55 \%$ while that of L3 increased to $16.98 \%$. From the 1990 s to the 2000 s, the share of L2 in this range again increased to $12.26 \%$ while that of L3 decreased to $13.21 \%$.

\section{Structural change and economic growth}

\subsection{Data and some preliminary processing}

The previous sections show both accelerating and decelerating patterns of structural change in the past 40 years in the Japanese economy. The structural change in capital stock decelerated almost constantly for the past 40 years, whereas that in value added has largely accelerated since the mid-1990s. The structural change in employment and capital-labour ratio changed in a cyclical manner for the past 40 years.

Along with the development of structural change, the growth patterns of value added and labour productivity have also changed over time. The previous section documents that while the growth process showed an overall even growth pattern during the 1970s and the 1980s, the process seems to have changed into an uneven pattern since the 1990s. During these processes, the durability of the sectoral order of contribution to growth in value added and labour productivity generally decreased in the long run.

The empirical questions in this section relate to (1) the type of structural change in output or inputs that had a significant impact on growth in value added and labour productivity, and (2) the magnitude of the structural changes in growth terms. Moreover, the previous section suggests the possibility of a transformation of growth pattern in value added and labour productivity at the beginning of the 1990s. Taking this into consideration, the next question is (3) whether there is a change in impact of structural change in input and output on these variables if we divide the whole period into sub-periods 1974-1991 and 1991-2010. This division at 1991 is mainly based on the bubble burst.

In order to examine these questions, we conduct a panel data analysis at the intermediate 
classification. All the variables are already introduced in the previous sections and are constructed on the basis of the JIP database 2014 of RIETI. Using the real value added, number of workers, man-hours, and real net capital stock from this database, we construct the following variables:

- $g_{V A}$ is the growth rate of real value added. The real value added is taken from the Growth accounting table (sheet name V), evaluated at 2000 prices. The real value added at intermediate classification is based on the sum of the real value added in the corresponding small classification. The growth rate of value added in each of the eight sectors is defined as its annual growth rate.

- $g_{L P}$ is the growth rate of labour productivity. Labour productivity is defined as the ratio of real value added to man-hours. The man-hours in the small classification is taken from the Labour input table (sheet name 3-8). Man-hours at the intermediate classification is evaluated in the same manner as with the value added. The growth rate of labour productivity in each of the eight sectors is defined as its annual growth rate.

- $M L I_{V A}$ and $N A V_{V A}$ are the modified Lilien index and norm of absolute value on real value added. Using the real value added mentioned above, we calculate these indices at intermediate classification from equations (1) and (2).

- $M L I_{E M P}$ and $N A V_{E M P}$ are the modified Lilien index and norm of absolute value on number of workers. We use the number of workers by sector in the Labour input table (sheet name 3-7) to calculate these indices. These indices at intermediate classification are calculated in the manner stated above.

- $M L I_{K P T}$ and $N A V_{K P T}$ are the modified Lilien index and norm of absolute value on capital stock. The capital stock variable is taken from the real net capital stock in the Growth accounting table (sheet name KT), evaluated at 2000 prices. These indices at intermediate classification are also calculated in the manner stated above.

- $M L I_{K L}$ and $N A V_{K L}$ are the modified Lilien index and norm of absolute value on the capitallabour ratio. The capital-labour ratio is defined as the ratio of real net capital to number of workers introduced above. These indices at intermediate classification are also calculated in the manner stated above. 
Table 4: Descriptive statistics for panel data analysis

\begin{tabular}{|c|c|c|c|c|c|c|c|c|c|c|}
\hline $1974-2010$ & $g_{L P}$ & $g_{V A}$ & $M L I_{V A}$ & $M L I_{E M P}$ & $M L I_{K P T}$ & $M L I_{K L}$ & $N A V_{V A}$ & $N A V_{E M P}$ & $N A V_{K P T}$ & $N A V_{K L}$ \\
\hline Mean & 0.032 & 0.029 & 0.031 & 0.010 & 0.010 & 0.018 & 0.034 & 0.011 & 0.011 & 0.019 \\
\hline Median & 0.019 & 0.020 & 0.020 & 0.008 & 0.008 & 0.014 & 0.024 & 0.010 & 0.009 & 0.016 \\
\hline Maximum & 2.240 & 2.200 & 0.527 & 0.045 & 0.058 & 0.124 & 0.530 & 0.037 & 0.053 & 0.117 \\
\hline Minimum & -0.709 & -0.695 & 0.005 & 0.000 & 0.001 & 0.002 & 0.005 & 0.000 & 0.001 & 0.002 \\
\hline Std. Dev. & 0.148 & 0.150 & 0.046 & 0.006 & 0.008 & 0.015 & 0.047 & 0.006 & 0.008 & 0.014 \\
\hline $1974-1991$ & $g_{L P}$ & $g_{V A}$ & $M L I_{V A}$ & $M L I_{E M P}$ & $M L I_{K P T}$ & $M L I_{K L}$ & $N A V_{V A}$ & $N A V_{E M P}$ & $N A V_{K P T}$ & $N A V_{K L}$ \\
\hline Mean & 0.038 & 0.044 & 0.035 & 0.010 & 0.014 & 0.021 & 0.038 & 0.011 & 0.015 & 0.022 \\
\hline Median & 0.022 & 0.029 & 0.021 & 0.009 & 0.011 & 0.018 & 0.025 & 0.009 & 0.013 & 0.020 \\
\hline Maximum & 2.240 & 2.200 & 0.527 & 0.045 & 0.058 & 0.124 & 0.530 & 0.037 & 0.053 & 0.117 \\
\hline Minimum & -0.709 & -0.695 & 0.005 & 0.002 & 0.002 & 0.002 & 0.005 & 0.003 & 0.003 & 0.003 \\
\hline Std. Dev. & 0.203 & 0.201 & 0.062 & 0.006 & 0.010 & 0.018 & 0.063 & 0.006 & 0.009 & 0.017 \\
\hline $1991-2010$ & $g_{L P}$ & $g_{V A}$ & $M L I_{V A}$ & $M L I_{E M P}$ & $M L I_{K P T}$ & $M L I_{K L}$ & $N A V_{V A}$ & $N A V_{E M P}$ & $N A V_{K P T}$ & $N A V_{K L}$ \\
\hline Mean & 0.025 & 0.015 & 0.027 & 0.010 & 0.007 & 0.015 & 0.030 & 0.011 & 0.008 & 0.016 \\
\hline Median & 0.017 & 0.012 & 0.020 & 0.008 & 0.006 & 0.012 & 0.024 & 0.010 & 0.007 & 0.014 \\
\hline Maximum & 0.451 & 0.584 & 0.105 & 0.044 & 0.028 & 0.079 & 0.133 & 0.036 & 0.025 & 0.069 \\
\hline Minimum & -0.108 & -0.149 & 0.006 & 0.000 & 0.001 & 0.002 & 0.007 & 0.000 & 0.001 & 0.002 \\
\hline Std. Dev. & 0.063 & 0.073 & 0.021 & 0.006 & 0.004 & 0.011 & 0.024 & 0.006 & 0.004 & 0.010 \\
\hline
\end{tabular}

Note: By author on the basis of JIP 2014. The computation is based on common samples in each period. The nuber of observation is 296,144 , and 160 in 1974-2010, 1974-1991 and 1991-2010, respectively.

Table 4 gives the descriptive statistics for panel data analysis, classified according to periods to be examined. A comparison of the 1974-1991 and 1991-2010 results shows clearly that the value of the mean, median, and standard division of all variables, except for employment in 1974-1991, is higher than that in 1991-2010. These values in 1974-2010 are almost the average of these two periods.

After constructing these variables and indices, we conduct panel unit root tests to confirm whether each has stationarity. As the panel data include both cross-sectional and time-series items, we need to consider whether these items have common unit root as well as individual unit root processes. Therefore, we conduct four types of panel unit root tests: The Levin, Lin, and Chu (LLC) and Breitung tests, which assume common unit roots in panel data, and the Im, Pesaran, and Shin and Fisher-type augmented Dickey-Fuller tests, which assume individual unit roots panel data.

The results are given in Table 8 in the appendix. With regard to all variables from 1973 to 2010, almost all tests reject the null hypothesis of both common and individual unit root process 
at the $1 \%$ significance level. With regard to the test for variables from 1973 to 1991 , the Breitung test for $M L I_{E M P}, M L I_{K P T}, N A V_{E M P}$, and $N A V_{K P T}$ cannot reject the common unit root process at the $10 \%$ significance level whereas the LLC test for these variable rejects the common unit root process at the $1 \%$ significance level. The Breitung test for $g_{V A}$ and $N A V_{K P T}$ from 1991 to 2010 also cannot reject the common unit root process at the $10 \%$ significance level. Moreover, all the four tests cannot reject the null hypothesis, meaning that $M L I_{K P T}$ in this period follows both common and individual unit root processes.

From these results, $M L I_{K P T}$ at level between 1991 and 2010 is not stationary, but the other variables at level are not necessarily non-stationary. Therefore, first, we estimate the relationship between the growth rates of value added and labour productivity and structural change at level. Second, we estimate the equation with $M L I_{K P T}$ for 1991-2010 by ensuring stationarity for this variable.

Let $i$ stand for the sectoral code and $t$ for time $t$. The equations in a panel data context to be estimated are either

$$
g_{i, t}=F\left(S C I_{V A, i t}, S C I_{E M P, i t}, S C I_{K P T, i t}\right)
$$

or

$$
g_{i, t}=F\left(S C I_{V A, i t}, S C I_{K L, i t}\right)
$$

where $g_{i, t}$ is a placeholder for different variables; it stands for the growth rate of either real value added or labour productivity. $S C I_{V A, i t}, S C I_{E M P, i t}, S C I_{K P T, i t}$, and $S C I_{K L, i t}$ are structural change indices of value added, employment, capital stock, and capital-labour ratio, respectively. As $S C I$, we employ the MLI and NAV mentioned above. $S C I_{V A, i t}$ represents the structural change in output, and we use $S C I_{E M P, i t}, S C I_{K P T, i t}$, and $S C I_{K L, i t}$ to examine the impact of structural change on input. Equations (7) and (8) are estimated alternatively. While equation (7) presents the role of inputs as separating type, equation (8) presents the role of inputs as ratio. Using the capital-labour ratio enables us to understand the impacts of technological changes in production on economic growth.

All estimations are built on the basis of balanced panel data. We assume that an equation has individual effect for both cross section and period. The effects specification follows the $\mathrm{Wu}-$ Hausman test, and this test for each equation indicates the random effect for each estimation. By 
controlling for both sectoral and periodical heterogeneity, the estimation here attempts to reveal the economy-wide relationship between growth and structural change.

\subsection{Results}

This section reports and discusses the finding of our empirical analysis. Table 5 shows the results for growth in value added and the structural change indices. Models 1 to 6 estimate these relationships using the MLI. To be more precise, models 1 and 2 show the results for the past 40 years, models 3 and 5 the results for 1974-1991, and models 4 and 6 the results for 1991-2010. The estimation is conducted alternatively between capital and labour separation and capital-labour ratio, according to equations (7) and (8). Table 5 also shows the results using the norm of absolute value in a similar manner with the MLI. Models 7 and 8 show the results for the past 40 years, models 9 and 11 the results for 1974-1991, and models 10 and 12 the results for 1991-2010. This estimation is also conducted alternatively, according to equations (7) and (8).

From table 5, the structural change in value added for all models commonly has a positive impact on growth in value added, and is always significant at the $1 \%$ level. This is true regardless of whether the models use $M L I$ and $N A V$ or are conducted separately for labour and capital and capital-labour ratio. On the contrary, the structural change in input has no significant impact on the growth in the value added. The coefficients on structural change in employment, capital, and capital-labour ratio are not significant in almost all models. The indices of structural change on employment have a negative sign, but are not significant at the $10 \%$ level. Only model 10 has a significant coefficient about the impact of structural change in inputs. This model indicates that the structural change in capital stock had a positive impact on growth in value added in 19912010 and it was significant at the $5 \%$ level. Generally, the structural change in output is more important than that in inputs to promote the growth in value added.

It is also important to note that the magnitude of the impact of structural change in value added on the growth rate changes between 1974-1991 and 1991-2010. The models with $M L I$ indicate that this impact was about 2 points in 1974-1991, but this decreased to about 1.3 points in 1991-2010. The models with $N A V$ also indicate that this impact was higher in 1974-1991 than in 1991-2010. In sum, the impact of structural change in output has been positive, but the magnitude of the impact has been weakened since 1991. By dividing the whole period into two sub-periods, we clearly find a change in impact of structural change in output on growth in value 
Table 5: Impact of structural change on growth in value added

\begin{tabular}{|c|c|c|c|c|c|c|}
\hline Model for $g_{V A}$ & model 1 & model 2 & model 3 & model 4 & model 5 & model 6 \\
\hline Period & $1974-2010$ & $1974-2010$ & 1974-1991 & $1991-2010$ & 1974-1991 & $1991-2010$ \\
\hline \multirow[t]{2}{*}{$C$} & -0.026 & $-0.034^{* *}$ & -0.006 & -0.028 & -0.032 & -0.013 \\
\hline & $(-1.455)$ & $(-2.358)$ & $(-0.193)$ & $(-1.592)$ & $(-1.444)$ & $(-0.781)$ \\
\hline \multirow[t]{2}{*}{$M L I_{V A}$} & $2.015^{* * *}$ & $1.997^{* * *}$ & $2.066^{* * *}$ & $1.326^{* * *}$ & $2.029^{* * *}$ & $1.347^{* * *}$ \\
\hline & $(12.82)$ & $(12.81)$ & $(9.597)$ & $(4.590)$ & $(9.657)$ & $(4.650)$ \\
\hline \multirow[t]{2}{*}{$M L I_{E M P}$} & -0.952 & & -1.643 & -0.861 & & \\
\hline & $(-0.799)$ & & $(-0.757)$ & $(-1.030)$ & & \\
\hline \multirow[t]{2}{*}{$M L I_{K P T}$} & 0.241 & & -0.322 & 2.448 & & \\
\hline & $(0.262)$ & & $(-0.243)$ & $(1.630)$ & & \\
\hline \multirow[t]{2}{*}{$M L I_{K L}$} & & 0.096 & & & 0.293 & -0.550 \\
\hline & & $(0.200)$ & & & $(0.399)$ & $(-1.075)$ \\
\hline Cross section & random & random & random & random & random & random \\
\hline Period & random & random & random & random & random & random \\
\hline No. of obs. & 296 & 296 & 144 & 160 & 144 & 160 \\
\hline Adj. $R^{2}$ & 0.356 & 0.355 & 0.390 & 0.124 & 0.392 & 0.112 \\
\hline Model for $g_{V A}$ & model 7 & model 8 & model 9 & model 10 & model 11 & model 12 \\
\hline Period & $1974-2010$ & $1974-2010$ & 1974-1991 & 1991-2010 & 1974-1991 & $1991-2010$ \\
\hline \multirow[t]{2}{*}{$C$} & -0.020 & $-0.033^{* *}$ & 0.011 & -0.031 & -0.029 & -0.006 \\
\hline & $(-0.969)$ & $(-2.103)$ & $(0.314)$ & $(-1.570)$ & $(-1.178)$ & $(-0.361)$ \\
\hline \multirow[t]{2}{*}{$N A V_{V A}$} & $1.897^{* * *}$ & $1.848^{* * *}$ & $1.992^{* * *}$ & $0.937^{* * *}$ & $1.877^{* * *}$ & $1.048^{* * *}$ \\
\hline & $(11.18)$ & (11.46) & $(8.346)$ & $(3.290)$ & $(8.643)$ & $(3.730)$ \\
\hline \multirow[t]{2}{*}{$N A V_{E M P}$} & -1.205 & & -2.528 & -0.437 & & \\
\hline & $(-0.870)$ & & $(-1.050)$ & $(-0.445)$ & & \\
\hline \multirow[t]{2}{*}{$N A V_{K P T}$} & -0.231 & & -0.906 & $2.920^{* *}$ & & \\
\hline & $(-0.226)$ & & $(-0.611)$ & $(1.794)$ & & \\
\hline \multirow[t]{2}{*}{$N A V_{K L}$} & & -0.062 & & & 0.072 & -0.701 \\
\hline & & $(-0.115)$ & & & $(0.089)$ & $(-1.216)$ \\
\hline Cross section & random & random & random & random & random & random \\
\hline Period & random & random & random & random & random & random \\
\hline No. of obs. & 296 & 296 & 144 & 160 & 144 & 160 \\
\hline Adj. $R^{2}$ & 0.306 & 0.306 & 0.346 & 0.081 & 0.342 & 0.071 \\
\hline
\end{tabular}

Note: Results used by Eviews 8. t-statistics is in parentheseis. ${ }^{* * *},{ }^{* *}$, and ${ }^{*}$ is statistically different from zero at 1 $\%, 5 \%$, and $10 \%$, repsectively. $\mathrm{C}$ is a constant term. Random refers to the random effects in effects specification in panel option. 
added.

Table 6 shows the results for growth in labour productivity and structural change indices. The table is constructed in the same manner as table 5. The indices of structural change on employment have a negative sign, but are not significant at the $10 \%$ level. The indices of structural change on capital stock and capital-labour ratio have both positive and negative signs, but they are not significant at the $10 \%$ level.

Only the structural change in output is significant to explain labour productivity growth. For all models, it is common that the structural change in value added has a positive impact on growth in labour productivity, and is always significant at the $1 \%$ level. Similar to the results for growth in value added, the structural change in output is more important than that in inputs to promote growth in labour productivity.

From Table 6, the magnitude of the impact of structural change in value added on labour productivity growth also changed between 1974-1991 and 1991-2010. The models with MLI indicate that this impact was about 2 points in 1974-1991, but it decreased to about 1.2 points in 1991-2010. The models with $N A V$ also indicate that this impact was also higher in 1974-1991 than in 1991-2010. The impact of structural change in output on labour productivity growth has been positive for the past 40 years. However, the magnitude of this impact has been weakened since 1991.

Finally, we conducted an additional test for this analysis. All the panel unit root tests indicate that $M P I_{K P T}$ for 1991-2010 is not stationary at level. As model 4 includes non-stationary variables for both value added and labour productivity growth, they may involve the so-called spurious regression problem. Therefore, we estimate this model again ensuring stationarity for all variables. The four types of panel unit root tests indicate that $M P I_{K P T}$ for 1991-2010 is stationary in its first difference form, although we do not report the result of the tests in a table.

Table 7 shows the results on this estimation. Similar to the original model 4 in tables 5 and 6 , only the structural change in output is positive and significant to explain the growth rate of value added and labour productivity. The coefficient on $S C I_{V A}$ is always significant at the $1 \%$ level. The structural change in output is still more important than that in inputs to promote economic growth. However, as with the original models, the magnitude of the impact of structural change in output on these growth rates is lower in 1991-2010 than in 1974-1991.

In addition to the above two econometric studies, we have evidence to show that in general a 
Table 6: Impact of structural change on growth in labour productivity

\begin{tabular}{|c|c|c|c|c|c|c|}
\hline Model for $g_{L P}$ & model 1 & model 2 & model 3 & model 4 & model 5 & model 6 \\
\hline Period & 1974-2010 & $1974-2010$ & 1974-1991 & $1991-2010$ & 1974-1991 & $1991-2010$ \\
\hline \multirow[t]{2}{*}{$C$} & -0.012 & $-0.030^{* *}$ & -0.003 & -0.007 & -0.037 & 0.002 \\
\hline & $(-0.739)$ & $(-2.496)$ & $(-0.104)$ & $(-0.444)$ & $(-1.673)$ & $(0.162)$ \\
\hline \multirow[t]{2}{*}{$M L I_{V A}$} & $1.986^{* * *}$ & $1.962^{* * *}$ & $2.036^{* * *}$ & $1.224^{* * *}$ & $2.023^{* * *}$ & $1.243^{* * *}$ \\
\hline & (12.99) & $(13.12)$ & $(9.317)$ & $(4.914)$ & $(9.463)$ & (5.096) \\
\hline \multirow[t]{2}{*}{$M L I_{E M P}$} & -0.899 & & -0.969 & -1.121 & & \\
\hline & $(-0.792)$ & & $(-0.440)$ & $(-1.548)$ & & \\
\hline \multirow[t]{2}{*}{$M L I_{K P T}$} & -0.860 & & -1.383 & 1.576 & & \\
\hline & $(-0.988)$ & & $(-1.027)$ & $(1.214)$ & & \\
\hline \multirow[t]{2}{*}{$M L I_{K L}$} & & 0.055 & & & 0.271 & -0.684 \\
\hline & & $(0.120)$ & & & $(0.363)$ & $(-1.545)$ \\
\hline Cross section & random & random & random & random & random & random \\
\hline Period & random & random & random & random & random & random \\
\hline No. of obs. & 296 & 296 & 144 & 160 & 144 & 160 \\
\hline Adj. $R^{2}$ & 0.365 & 0.367 & 0.383 & 0.132 & 0.382 & 0.137 \\
\hline Model for $g_{L P}$ & model 7 & model 8 & model 9 & model 10 & model 11 & model 12 \\
\hline Period & $1974-2010$ & $1974-2010$ & 1974-1991 & $1991-2010$ & 1974-1991 & 1991-2010 \\
\hline \multirow[t]{2}{*}{$C$} & -0.005 & $-0.027^{* *}$ & 0.015 & -0.013 & -0.034 & 0.004 \\
\hline & $(-0.288)$ & $(-2.128)$ & $(0.432)$ & $(-0.855)$ & $(-1.405)$ & $(0.301)$ \\
\hline \multirow[t]{2}{*}{$N A V_{V A}$} & $1.865^{* * *}$ & $1.805^{* * *}$ & $1.957^{* * *}$ & $1.045^{* * *}$ & $1.876^{* * *}$ & $1.123^{* * *}$ \\
\hline & (11.59) & (11.92) & $(8.112)$ & $(4.487)$ & $(8.514)$ & (4.973) \\
\hline \multirow[t]{2}{*}{$N A V_{E M P}$} & -1.117 & & -1.711 & -0.739 & & \\
\hline & $(-0.894)$ & & $(-0.703)$ & $(-0.884)$ & & \\
\hline \multirow[t]{2}{*}{$N A V_{K P T}$} & -1.338 & & -2.108 & 1.919 & & \\
\hline & $(-1.445)$ & & $(-1.407)$ & (1.423) & & \\
\hline \multirow[t]{2}{*}{$N A V_{K L}$} & & -0.172 & & & 0.063 & -0.790 \\
\hline & & $(-0.345)$ & & & $(0.077)$ & $(-1.630)$ \\
\hline Cross section & random & random & random & random & random & random \\
\hline Period & random & random & random & random & random & random \\
\hline No. of obs. & 296 & 296 & 144 & 160 & 144 & 160 \\
\hline Adj. $R^{2}$ & 0.332 & 0.326 & 0.344 & 0.120 & 0.336 & 0.126 \\
\hline
\end{tabular}

Note: Results used by Eviews 8. t-statistics is in parentheseis. ${ }^{* * *},{ }^{* *}$, and ${ }^{*}$ is statistically different from zero at 1 $\%, 5 \%$, and $10 \%$, repsectively. $\mathrm{C}$ is a constant term. Random refers to the random effects in effects specification in panel option. 
Table 7: Impact of structural change on growth in value added and labour productivity (additional estimation)

\begin{tabular}{|c|c|c|}
\hline & model for $g_{V A}$ & model for $g_{L P}$ \\
\hline Period & $1991-2010$ & 1991-2010 \\
\hline \multirow[t]{2}{*}{$C$} & -0.014 & 0.002 \\
\hline & $(-0.972)$ & $(0.127)$ \\
\hline \multirow[t]{2}{*}{$M L I_{V A}$} & $1.387^{* * * *}$ & $1.259^{* * *}$ \\
\hline & $(4.886)$ & $(5.072)$ \\
\hline \multirow[t]{2}{*}{$M L I_{E M P}$} & -0.824 & -1.043 \\
\hline & $(-0.983)$ & $(-1.441)$ \\
\hline \multirow[t]{2}{*}{$d\left(M L I_{K P T}\right)$} & 0.528 & 0.181 \\
\hline & $(0.301)$ & $(0.121)$ \\
\hline Cross section & random & random \\
\hline Period & random & random \\
\hline No. of obs. & 160 & 160 \\
\hline Adj. $R^{2}$ & 0.116 & 0.127 \\
\hline
\end{tabular}

Note: Results used by Eviews 8. t-statistics is in parentheseis. $d()$ is an operator to take first difference on the variable. ${ }^{* * *},{ }^{* *}$, and ${ }^{*}$ is statistically different from zero at $1 \%, 5 \%$, and $10 \%$, repsectively. C is a constant term. Random refers to the random effects in effects specification in panel option. 
structural change in output rather than in inputs causes growth in value added and labour productivity. However, the positive impact of structural change in output has not always been effective, with the magnitude of growth in both value added and labour productivity weakened after the 1990s.

\section{Conclusion}

It is important to consider the industrial structure in economic growth regime analysis because sectoral heterogeneity matters in the Japanese economy, especially after the 1990s, as the current study shows. The current study investigated the structural change in inputs and output in the Japanese economy for the past 40 years. We are also concerned with the sectoral and macroeconomic growth process in value added and labour productivity. Moreover, by way of panel data analysis, we find evidence for the relationship between structural change and economic growth.

The main findings of this study are as follows. (1) The pace of structural change in value added was relatively stable until the 1990s and then has sped up since the 2000s, while the pace of structural change in capital stock decreased constantly since the 1970s. (2) The sectoral dispersion in value added and labour productivity clearly reduced until the mid-1980s but has increased since the 2000s. (3) The sectoral contribution to growth in value added and labour productivity shows a different pattern before and after 1990. There was an overall growth process in the 1970s and 1980s, but an uneven growth process in the 1990s and 2000s. (4) The structural change in output is more important than that in inputs to promote economic growth. However, its positive impact on growth has weakened since the 1990s.

How do we characterize the growth regime in the Japanese economy in terms of growth process and industrial structure? The results in the current study suggest that there was a break in growth process in the 1990s. As we mentioned earlier, the growth process in value added and labour productivity was relatively uniform before the 1990s. Almost all sectors in the economy positively contributed to growth in these terms during the 1970s and 1980s, and this process accompanied a decrease in sectoral dispersion in value added and labour productivity. On the contrary, the growth in value added and labour productivity after the 1990s was uneven. The number of sectors that positively contributed to growth in value added and labour productivity has decreased since the 1990s, and this process accompanied an increase in sectoral dispersion 
in value added and labour productivity, especially in the 2000 s.

Taking these into consideration, the growth regime before the 1990s can be characterized as a heterogeneity decreased one with overall growth process. To use Herberger (1998)'s metaphor, it corresponds to the yeast-type growth process, in which most sectors positively contribute to economic growth. In contrast, the growth regime after the 1990s can be characterized as a heterogeneity increased regime with uneven growth process. Using Herberger (1998)'s metaphor, it corresponds to the mushroom-type growth process, in which only limited sectors positively contribute to economic growth.

As a result of this heterogeneous structure, the recent growth regime in the Japanese economy could not be sufficiently established. The leading sectors in the 2000 s were from the export-core sector, but it is a rather externally depending sector. In a heterogeneity increased regime in which only limited sectors, including this sector, contributed to growth, the stagnation of leading sectors may accelerate the depression of the overall economy. This means that the economy would simply lose its leading pillars, and there would remain only stagnating sectors. On the contrary, a heterogeneity decreased regime is not as vulnerable as this regime, because most sectors positively contribute to growth. Even if a part of the leading sectors stagnates, the other positive part may compensate for such stagnation, and the growth can still be sustained. The Japanese economy needs to realize sustainable growth, and the warped relation between industrial structure and economic growth should be rebalanced.

In addition to change in industrial structure, the impact of structural change should also be enhanced. As the panel data analysis in the current study showed, even if there is a structural change in inputs, it does not contribute to economic growth significantly. Rather, a structural change in output can have a positive impact on economic growth. However, the problem is that such impacts have weakened since the 1990s compared to earlier periods. The structural change in output is related to innovation that improves the sectors' product quality and attracts new consumer preferences. The importance of such innovation that creates new effective demand in existing and new sectors has been emphasized by Pasinetti (1993) and Yoshikawa (2003). A demand-creating innovation can create or shift new demand between sectors and cause structural change in value added. Our empirical results suggest that such innovations are necessary to sustain the economic growth of Japan. 


\section{References}

Ansari, M., C. Mussida and F. Pastore (2013): 'Note on Lilien and Modified Lilien Index', IZA Discussion Paper (7198), pp. 1-9, February.

Baily, M., C. Hulten and D. Campbell (1992): 'Productivity Dynamics in Manufacturing Plants', Brookings Papers on Economic Activity: Microeconomics, pp. 187-267.

Baumol, W. (1967): 'Macroeconomics of Unbalanced Growth: The Anatomy of Urban Crisis', American Economic Review, 57 (3), pp. 415-426.

Baumol, W., S. Blackman and E. Wolff (1985): 'Unbalanced Growth Revisited: Asymptotic Stagnancy and New Evidence', American Economic Review, 75 (4), pp. 806-817.

Boyer, R., H. Uemura and A. Isogai eds. (2011): Diversity and Transformations of Asian Capitalisms: A de Facto Regional Integration, London: Routledge.

Boyer, R. and T. Yamada eds. (2000): Japanese Capitalism in Crisis: A Régulationist Interpretation, London: Routledge.

Chenery, H. and T. Srinivasan eds. (1988): Handbook of Development Economics, 1, Amsterdam: North Holland.

Dietrich, A. (2012): 'Does Growth Cause Structural Change, or is it the Other Way Around? A Dynamic Panel Data Analysis for Seven OECD Countries', Empirical Economics, 43, pp. 915-944.

Franke, R. and P. Kalmbach (2005): 'Structural Change in the Manufacturing Sector and Its Impact on Business-Related Services: An Input-Output Study for Germany', Structural Change and Economic Dynamics, 16 (4), pp. 467-488.

Fukao, K. (2012): Lost Two Decades and Japanese Economy, Tokyo: Nihonkeiazi Shinbunsha. (in Japanese).

Fukao, K. and T. Miyagawa eds. (2008): Productivity and Japanese Economic Growth: Empirical Analysis at Industrial and Firm Level Using JIP Database, Tokyo: Tokyo University Press. (in Japanese). 
Hartwig, J. (2011): 'Testing the Baumol-Nordhaus Model with EU KLEMS Data', Review of Income and Wealth, 57 (3), pp. 471-489.

(2012): 'Testing the Growth Effects of Structural Change', Structural Change and Economic Dynamics, 23 (1), pp. 11-24.

Hein, E. (2014): Distribution and Growth after Keynes, Cheltenham: Edward Elgar.

Herberger, A. (1998): 'A Vision of the Growth Process', American Economic Review, 88 (1). $1-32$.

Inklaar, R. and M. Timmer (2007): 'Of Yeast and Mushrooms: Patterns of Industry-Level Productivity Growth', German Economic Review, 8 (2), pp. 174-187.

Ito, K. and S. Lechevalier (2009): 'The Evolution of the Productivity Dispersion of Firms: A Reevaluation of Its Determinants in the case of Japan', Review of World Economy, 145 (3), pp. 405-429.

Krüger, J. (2008a): 'Productivity and Structural Change: A Review of the Literature', Journal of Economic Surveys, 22 (2), pp. 330-363.

_ (2008b): 'The Sources of Aggregate Productivity Growth: US Manufacturing Industries, 1958-1996', Bulletin of Economic Research, 60 (4), pp. 405-427.

Lavoie, M. and E. Stockhammer eds. (2013): Wage-led Growth: An Equitable Strategy for Economic Recovery, New York: Palgrave Macmillan.

Lilien, D. (1982): 'Sectoral Shifts and Cyclical Unemployment', Journal of Political Economy, 90 (4), pp. 777-793.

Morikawa, M. (2014): Productivity Analysis in Service Industries: An Empirical Analysis Using Microdata, Tokyo: Nihon hyorosha. (in Japanese).

Nordhaus, W. (2008): 'Baumol's Diseases: A Macroeconomics Perspective', The B.E. Journal of Macroeconomics, 8 (1), pp. 1-37.

Pasinetti, L. (1993): Structural Economic Dynamics: A Theory of the Economic Consequences of Human Learning, Cambridge: Cambridge University Press. 
Peneder, M. (2003): 'Industrial Structure and Aggregate Growth', Structural Change and Economic Dynamics, 14 (4), pp. 427-448.

Prasad, E. (1997): 'Sectoral Shifts and Structural Change in the Japanese Economy: Evidence and Interpretation', Japan and the World Economy, 9, pp. 293-313.

Rowthorn, R. E. and J. R. Wells (1987): De-industrialization and Foreign Trade, Cambridge: Cambridge University Press.

Maroto-Sánchez, A. and J.R. Cuadrado-Roura (2009): 'Is Growth of Services an Obstacle to Productivity Growth? A comparative Analysis', Structural Change and Economic Dynamics, 20 (4), pp. 254-265.

Syrquin, M. (1988): 'Patterns of Structural Change', pp. 203-273. in Chenery and Srinivasan (1988).

Timmer, M., R. Inklaar, M. O’Mahony and B. van Ark eds. (2013): Economic Growth in Europe: A Comparative Industry Perspective, Cambridge: Cambridge University Press.

Uemura, H. and S. Tahara (2014): 'The Transformation of Growth Regime and Deindustrialization in Japan', Revue de la Régulation, 15 (1).

Uni, H. (2011): 'Increasing Wage Inequality in Japan since the End of the 1990s: An Institutional Explanation', pp. 90-106. in Boyer et al. (2011).

Wolff, E. (2002): 'Computerization and Structural Change', Review of Income and Wealth, 48 (1), pp. 59-75.

Yoshikawa, H. (2003): 'Role of Demand in Macroeconomics', Japanese Economic Review, 54 (1), pp. 1-27.

\section{Appendix}

In this appendix, we report the unit root test results of the panel data analysis in section 4 . We conducted four types of panel unit root tests. The Levin, Lin, and Chu (LLC) and the Breitung 
tests are used for common unit roots in panel data, and the Im, Pesaran, and Shin and the Fishertype augmented Dickey-Fuller tests are used for individual unit roots panel data. All the tests include an individual intercept and trend in test equation. The lag length in these tests is selected by automatic lag length selection based on Schwarz information criterion.

Table 8: Panel unit root tests

\begin{tabular}{|c|c|c|c|c|c|c|c|c|c|c|}
\hline $1973-2010$ & $g_{V A}$ & $g_{L P}$ & $M L I_{V A}$ & $M L I_{E M P}$ & $M L I_{K P T}$ & $M L I_{K L}$ & $N A V_{V A}$ & $N A V_{E M P}$ & $N A V_{K P T}$ & $N A V_{K L}$ \\
\hline LLC & $-9.768^{* * *}$ & $-9.965^{* * *}$ & $-12.59^{* * *}$ & $-6.713^{* * *}$ & $-2.089^{* *}$ & $-3.687^{* * *}$ & $-11.24^{* * *}$ & $-5.392^{* * *}$ & $-1.958^{* *}$ & $-3.265^{* * *}$ \\
\hline Breitung & $-4.526^{* * *}$ & $-6.081^{* * *}$ & $-4.555^{* * *}$ & $-4.480^{* * *}$ & $-3.356^{* * *}$ & $-2.299^{* *}$ & $-4.670^{* * *}$ & $-3.977^{* * *}$ & $-2.470^{* * *}$ & $-2.455^{* * *}$ \\
\hline IPS & $-10.78^{* * *}$ & $-11.25^{* * *}$ & $-10.943^{* * *}$ & $-8.364^{* * *}$ & $-2.788^{* * *}$ & $-4.095^{* * *}$ & $-10.96^{* * *}$ & $-7.330^{* * *}$ & $-2.796^{* * *}$ & $-3.717^{* * *}$ \\
\hline $\mathrm{ADF}$ & $123.1^{* * *}$ & $127.4^{* * *}$ & $148.1^{* * *}$ & $96.00^{* * *}$ & $36.21^{* * *}$ & $46.99^{* * *}$ & $136.9^{* * *}$ & $82.99^{* * *}$ & $37.08^{* * *}$ & $44.26^{* * *}$ \\
\hline 1973-1991 & $g_{V A}$ & $g_{L P}$ & $M L I_{V A}$ & $M L I_{E M P}$ & $M L I_{K P T}$ & $M L I_{K L}$ & $N A V_{V A}$ & $N A V_{E M P}$ & $N A V_{K P T}$ & $N A V_{K L}$ \\
\hline LLC & $-6.936^{* * *}$ & $-6.152^{* * *}$ & $-6.748^{* * *}$ & $-6.553^{* * *}$ & $-3.893^{* * *}$ & $-4.018^{* * *}$ & $-5.495^{* * *}$ & $-5.426^{* * *}$ & $-3.118^{* * *}$ & $-2.327^{* * *}$ \\
\hline Breitung & $-2.535^{* * *}$ & $-3.648^{* * *}$ & $-4.254^{* * *}$ & -0.836 & -1.246 & $-4.551^{* * *}$ & $-4.293^{* * *}$ & 0.611 & -0.996 & $-2.962^{* * *}$ \\
\hline IPS & $-5.428^{* * *}$ & $-4.200^{* * *}$ & $-6.002^{* * *}$ & $-6.746^{* * *}$ & $-3.337^{* * * *}$ & $-3.715^{* * *}$ & $-5.080^{* * *}$ & $-4.742^{* * *}$ & $-3.132^{* * *}$ & $-3.770^{* * *}$ \\
\hline $\mathrm{ADF}$ & $55.31^{* * *}$ & $45.54^{* * *}$ & $60.31^{* * *}$ & $68.22^{* * *}$ & $41.57^{* * *}$ & $39.30^{* * *}$ & $53.06^{* * *}$ & $53.16^{* * *}$ & $40.29^{* * *}$ & $39.88^{* * *}$ \\
\hline $1991-2010$ & $g_{V A}$ & $g_{L P}$ & $M L I_{V A}$ & $M L I_{E M P}$ & $M L I_{K P T}$ & $M L I_{K L}$ & $N A V_{V A}$ & $N A V_{E M P}$ & $N A V_{K P T}$ & $N A V_{K L}$ \\
\hline LLC & $-6.899^{* * *}$ & $-5.981^{* * *}$ & $-7.028^{* * *}$ & $-3.328^{* * *}$ & -1.000 & $-5.137^{* * *}$ & $-5.055^{* * *}$ & $-3.039^{* * *}$ & $-2.528^{* * *}$ & $-5.055^{* * *}$ \\
\hline Breitung & -0.755 & $-1.809^{* *}$ & $-2.749^{* * *}$ & $-1.858^{* *}$ & 0.361 & $-1.821^{* *}$ & $-3.913^{* * *}$ & $-1.530^{*}$ & -0.110 & $-3.913^{* * * *}$ \\
\hline IPS & $-6.843^{* * *}$ & $-6.190^{* * *}$ & $-6.569^{* * *}$ & $-3.320^{* * *}$ & -0.682 & $-4.835^{* * *}$ & $-7.257^{* * *}$ & $-3.371^{* * *}$ & $-2.751^{* * *}$ & $-7.257^{* * *}$ \\
\hline $\mathrm{ADF}$ & $70.58^{* * *}$ & $62.91^{* * *}$ & $66.33^{* * *}$ & $41.49^{* * *}$ & 21.30 & $51.13^{* * *}$ & $71.29^{* * *}$ & $41.58^{* * *}$ & $36.96^{* * *}$ & $71.29^{* * *}$ \\
\hline
\end{tabular}

Note: LLC represents Levin, Lin and Chu test. LLC test and Breitung test both assume common unit root process in the panel unit root test. IPS represents Im, Pesaran and Shin test, and ADF represents Fisher type augmented Dickey-Fuller test. The IPS and ADF assumes individual unit root process in the panel unit root test. Significance at $1 \%$, at $5 \%$ and at $10 \%$ level is denoted by ${ }^{* * *},{ }^{* *}$ and ${ }^{*}$, repsectively.

Table 8 shows the test statistics and unit root test results in level by the periods to be examined (i.e., 1973-2010, 1973-1991, and 1991-2010). Almost all tests for the variables from 1973 to 2010 reject the null hypothesis of both common and individual unit root processes at the $1 \%$ significance level. The Breitung test for $M L I_{E M P}, M L I_{K P T}, N A V_{E M P}$, and $N A V_{K P T}$ from 1973 to 1991 cannot reject the common unit root process at the $10 \%$ significance level, whereas the LLC test for these variables reject the common unit root process at the $1 \%$ significance level. The Breitung test for $g_{V A}, M L I_{K P T}$, and $N A V_{K P T}$ from 1991 to 2010 cannot reject the common unit root process at the $10 \%$ significance level. Moreover, all the four tests cannot reject that $M L I_{K P T}$ in this period follows both common and individual unit root processes. 